\title{
Vineyard properties extraction combining UAS- based RGB imagery with elevation data
}

Luís Pádua, Pedro Marques, Jonáš Hruška, Telmo Adão, José Bessa, António Sousa, Emanuel Peres, Raul Morais \& Joaquim J. Sousa

To cite this article: Luís Pádua, Pedro Marques, Jonáš Hruška, Telmo Adão, José Bessa, António Sousa, Emanuel Peres, Raul Morais \& Joaquim J. Sousa (2018): Vineyard properties extraction combining UAS-based RGB imagery with elevation data, International Journal of Remote Sensing, DOI: $10.1080 / 01431161.2018 .1471548$

To link to this article: https://doi.org/10.1080/01431161.2018.1471548

曲 Published online: 10 May 2018.

Submit your article to this journal $\pi$

Q View related articles $₫$

View Crossmark data $\nearrow$ 


\title{
Vineyard properties extraction combining UAS-based RGB imagery with elevation data
}

\author{
Luís Pádua (10 ${ }^{a}$, Pedro Marques ${ }^{a}$, Jonáš Hruškaa, Telmo Adão $\mathbb{1}^{\mathrm{a}, \mathrm{b}}$, José Bessa ${ }^{\mathrm{a}}$,

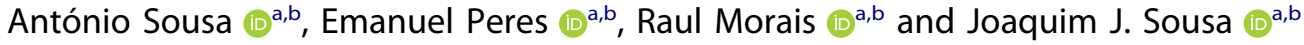 \\ ${ }^{a}$ School of Science and Technology, University of Trás-os-Montes e Alto Douro, Vila Real, Portugal; bentre \\ for Robotics in Industry and Intelligent Systems (CRIIS), INESC Technology and Science (INESC-TEC), Porto, \\ Portugal
}

\begin{abstract}
To differentiate between canopy and vegetation cover is particularly challenging. Nonetheless, it is pivotal in obtaining the exact crops' vegetation when using remote-sensing data. In this article, a method to automatically estimate and extract vineyards' canopy is proposed. It combines vegetation indices and digital elevation models - derived from high-resolution images, acquired using unmanned aerial vehicles - to differentiate between vines' canopy and inter-row vegetation cover. This enables the extraction of relevant information from a specific vineyard plot. The proposed method was applied to data acquired from some vineyards located in Portugal's north-eastern region, and the resulting parameters were validated. It proved to be an effective method when applied with consumer-grade sensors, carried by unmanned aerial vehicles. Moreover, it also proved to be a fast and efficient way to extract vineyard information, enabling vineyard plots mapping for precision viticulture management tasks.
\end{abstract}

\section{ARTICLE HISTORY}

Received 29 September 2017 Accepted 22 April 2018

\section{Introduction and background}

Requirements to optimize vineyards' (Vitis vinifera L.) performance in a precision viticulture (PV) context are high because both yield and quality should be maximized, while environmental risks and impacts should be reduced (Proffitt et al. 2006). Therefore, farmers achieve the utmost control over vineyard management by considering its variability. Grapevine quality and development directly relate with the vineyards' spatial heterogeneity, which depends on several factors associated to the vineyard itself - soil, crop management, irrigation, nutritional status, pest and disease control, and external variables, as the climate - to determine the inter-annual and intra-vineyard variability of both yield and quality (Matese et al. 2015). These factors can lead to the occurrence of biotic and abiotic issues. Depending on their severity, they can result in a significant production decrease and consequently in significant economic losses (Baofeng et al. 2016). Recent technological development opened the possibility of implementing both precision agriculture (PA) and PV, along with the combination of certain procedures, to

CONTACT Joaquim J. Sousa jjsousa@utad.pt $\Theta$ School of Science and Technology, University of Trás-os-Montes e Alto Douro, Vila Real, Portugal 
improve the decision-making process in several field-related tasks (Zarco-Tejada, Hubbard, and Loudjani 2014). Hence, remote-sensing data can provide a better understanding of a terrain's variability and can be applied in the context of PV management (Bobillet et al. 2003). Indeed, sensors used in remote-sensing platforms provide an effective way to extract spatial information about crops' state in a non-destructive manner (Weiss and Baret 2017).

Regarding vineyards, the usage of remote-sensing platforms is usually related to grape varieties mapping (Lacar, Lewis, and Grierson 2001); vineyard leaf area index (LAI) estimation (Johnson et al. 2003; Kalisperakis et al. 2015; Mathews and Jensen 2013); irrigation scheduling and water stress variability (Baluja et al. 2012; Bellvert and Girona 2012; Bellvert et al. 2013; Zarco-Tejada, Berjón, and Miller 2004); grapevine phenology monitoring (Fraga et al. 2014; Lamb, Weedon, and Bramley 2004); disease detection and mapping (Albetis et al. 2017; Matese et al. 2013); grape quality mapping in vineyards affected by nutrient deficiency (Martín et al. 2015); and chlorophyll estimation (Zarco-Tejada et al. 2005), among others. However, the use of remote-sensing techniques is challenging due to the alternation of vines' canopies - which form a set of parallel rows - along with the presence of bare soil or vegetation cover, within the vineyard plot (Burgos et al. 2015; Matese et al. 2015). By considering the whole vineyard terrain, the presence of information other than vines' canopy is added, i.e. the inter-row vegetation cover and shadows produced by vines' canopy and its surroundings. To detect vine's canopy, several authors and research teams proposed approaches based on the use of vegetation indices (VIs) applied to the imagery data provided by remotesensing platforms (Albetis et al. 2017; Bellvert and Girona 2012; Fraga et al. 2014; Johnson et al. 2003; Matese et al. 2015; Naidu et al. 2009; Smit, Sithole, and Strever 2010). Vls are simple arithmetic operations applied to the spectral narrow-band or broad-band imagery, with information from different parts of the electromagnetic spectrum (Pádua et al. 2017). However, Vls are often computed over the whole vineyard or at the plot level. Thus, information not related with vines is present. To produce correct vineyard maps, a separation of vine pixels from non-vine pixels in the remotesensing data is required. Although feasible manually, it is a laborious, error-prone, and time-consuming task. Still, it is crucial since it heavily contributes to the obtained results' global accuracy, which, in turn, increases vineyards' management efficiency by providing information about crops' variability. This enables the application of more efficient treatments to the plants and autonomous guidance for unmanned ground vehicles.

Considering the previously presented requirements, satellite imagery is not suitable for vineyards' management tasks. The spatial resolution provided is, in general, too sparse (Matese et al. 2015) and the data acquisition frequency too low. Manned aircrafts and Unmanned Aerial Systems (UAS) provide more timely and flexible data acquisition solutions (Weiss and Baret 2017). While manned aircrafts can cover larger areas with high resolution, they can be expensive for small-sized projects (Pádua et al. 2017). On the other hand, the ability of UAS (Unnamed Aerial Vehicle [UAV] + sensors and ground control station) to perform low-altitude flights - enabling the acquisition of very high-resolution data - makes them an ideal tool to use when versatility, cost-effectiveness, and temporal data are needed.

To overcome the vine's vegetation identification issue, different studies proposed (semi)automatic methods, using image-processing techniques on a single-band image, Vis, or digital elevation models (DEMs). Bobillet et al. (2003) proposed a method to 
classify vine rows based on vineyards' active contours. This method's main issue was the requirement of manual adjustments in pre- and post-processing stages to achieve valid results. Furthermore, problems identifying vine rows with grass in-between them were also reported. Chanussot, Bas, and Bombrun (2005) studied the identification of missing vines and proposed a method that uses the Radon transform of the Fourier spectrum over a vineyard's image. This image is computed by subtracting the red band from the green band of the RGB image. The process allowed finding both the inter-row spacing and row orientation. Next, a set of morphological operations and a median filter over a binary image generate an image that signals missing vines. However, this method reportedly fails when dealing with irregularly spaced, too sparse, or curved plantations. Comba et al. (2015) proposed a method that benefits from vegetation's high reflectance in near-infrared (NIR) imagery to apply the Hough space clustering over an image. This image is a result of local histogram equalization thresholding to estimate vine's canopy vegetation and total least squares technique to estimate vine rows. The method uses techniques that require a large amount of processing time in big areas or images with lower ground sample distance (GSD) values. The method developed by Comba et al. (2015) was also applied in other studies to produce vigour maps (Primicerio et al. 2015) and to estimate vines positions in a vineyard (Primicerio et al. 2017). In the latter, the trunk's position was estimated along with the canopy shape of each individual plant. It was assumed that the plants are equally spaced along each vine row, which enabled the application of a machine learning procedure to discriminate between the presence or the absence of a plant along a row. Nolan et al. (2015) used skeletonization techniques to accurately segment vineyard rows for vineyard mapping. The proposed method used single-band images from distinct types of sensors as inputs, with the only requirement of having a high spatial resolution to distinguish vine rows from soil. The reported failure rate was related with the presence of trees obscuring vine rows, shadows, and segmentation discontinuities. To detect vine rows, Puletti, Perria, and Storchi (2014) proposed a method that considers the lower reflectance values from the vineyard canopy red channel and the soil's high reflectance. An image obtained by a high-pass filter is then processed and passed to a modified version of Ward's technique (Ward 1963), which provides an unsupervised hierarchical cluster analysis. There were problems reported in areas with low contrast between vineyard canopy and soil. Poblete-Echeverría et al. (2017) studied different approaches to perform vineyard vegetation detection, using VIs and both supervised (artificial neural networks and Random Forests) and unsupervised (k-means clustering) classification methods in three classes: plant, shadow, and soil. The obtained results showed that the combination of VIs with artificial neural networks provided good results. Poblete-Echeverría et al. (2017) stated that supervised classification methods needed human intervention for model calibration with a training data set. On the other hand, Vls complemented with the Otsu's method (Otsu 1979) for thresholding, had a higher overall accuracy, and performed very well in the detection of vineyards' canopy. This resulted in an easy and automatic method for vine vegetation extraction, even though VIs can also classify vegetation with the same reflectance in between vine rows.

The problem of inter-row vegetation classification can be surmounted with a more straightforward method: using DEMs computed from the photogrammetric processing of UAV-based imagery and by considering the vineyard plot structure's height. DEMs are 
an accurate representation of the surface elevation. They can provide terrain's surface elevation data - digital terrain model (DTM) - and contain elevation data from features present in the ground surface - digital surface model (DSM). Using this type of data, Kalisperakis et al. (2015) were able to estimate vineyards' LAl, achieving good correlation rates when compared with ground-truth measurements, whereas hyperspectral and RGB imagery obtained lower correlation rates. Burgos et al. (2015) used this type of data to separate non-vine pixels from vine pixels, by producing a Digital Differential Model that results from subtracting the DTM from the DSM - also known as Canopy Height Model or Crop Surface Model (CSM), CSM will be the terminology used in this study. To assess CSM obtained from photogrammetric processing of UAS-based multispectral data in a vineyard plot, Matese, Gennaro, and Berton 2016 found a relationship between vines' heights - obtained from CSM - and normalized difference vegetation index (NDVI) values: higher vegetation heights coincided with higher NDVI values. Moreover, the authors also shown that UAS are suitable for vineyard's biomass estimation. However, flight altitude allied with the sensor's resolution caused a smoothness on the DSM, which lead the authors to consider only a vegetation's height above $0.5 \mathrm{~m}$. In (Burgos et al. 2015; Kalisperakis et al. 2015; Matese, Gennaro, and Berton 2016), elevation data obtained from the UAS proved to be an effective technique to estimate vineyard's vegetation, regardless of the terrain slope or outliers. Baofeng et al. (2016) proposed a method that used the DSM to estimate missing plants and plants potentially affected from biotic and abiotic problems. The method relied on the DSM's local normalization with a sliding window to remove the terrain slope effect, transforming it in a binary image that differentiates vine from non-vine pixels. This approach requires the image to be both inverted and rotated to get a vertical row alignment and divided into a grid. If the non-vine pixels percentage is greater than $90 \%$, it is considered as missing vine, whereas if it is between $20 \%$ and $90 \%$, it is deemed to be affected vine. Weiss and Baret (2017) processed UAV-based RGB imagery to extract the vineyard's macrostructure, vine row orientation, cover fraction, row width, row spacing, percentage of vegetation, and missing vegetation. The method analyses the percentage of points in the processed dense-point cloud, where a threshold was used to separate vine row pixels from background pixels. This method also requires vertical vine row alignment, obtained by estimating the row orientation using the Hough transform. Thus, row spacing results from using row peaks' average value from a horizontal profile line. Moreover, a cover fraction estimation results from dividing the estimated row width by the row spacing or by computing the ratio between the number of pixels estimated as vineyard vegetation and the total number of pixels in the image. Missing plants calculation was done by individual analysis of each row based on the percentage of non-vegetation pixels. This procedure, as stated by the authors, is not very sensitive to large variations of row width and height. However, depending on the flight characteristics (image overlapping, altitude, sensor, and data processing software) and of the vineyard management practices or its phenological cycle, produced elevation models can be imprecise, rendering them unable to differentiate accurately between vines and soil.

The aforementioned studies show the diversity of methodologies found in literature concerning the segmentation of vine rows and vineyard vegetation. Each has their own strengths and weaknesses, and this work uses them in a complementary way, especially UAS-based methodologies. Indeed, photogrammetric processing of imagery - acquired 
during an aerial survey, as point cloud(s) - along with individual UAV imagery, can be used to compute orthophoto mosaics, DTMs, and 3D models of the surveyed area (Pádua et al. 2017). By combining the very high-resolution outcomes produced from UAVs imagery, the proposed method's main goals are to (1) identify and extract vineyard's vegetation by distinguishing it from soil, canopy shadow, and eventual inter-row vegetation; (2) detect vine rows for a given vineyard plot; and (3) estimate possible missing vine plants.

The proposed method works independently from the type of broadband imagery sensor coupled to the UAV, the vineyard plot orientation, and terrain slope. In addition, it uses as few parameters as possible to be robust enough to achieve the defined goals. Finally, the proposed method also considers the potential of imagery data to estimate vineyard parameters. Thus, combining VIs with elevation data to provide accurate vineyard maps may be used to extract vineyard-related parameters in the scope of PV, helping in both the management and decision-making tasks. The proposed method proved to be effective when applied with low-cost consumer-grade sensors carried by UAVs.

This article is structured in six sections. In this section, the motivation and main goals were described, along with some related works and applications of remote sensing in PV, which enabled to assess the actual state-of-the-art. Section 2 describes the data acquisition process, the used UAV platforms, and the vineyard data used in the study. Section 3 presents an evaluation of the different VIs' suitability to detect vineyard vegetation. Then, the proposed method is described in Section 4. Section 5 presents the results, validation, and discussion of the proposed method, when applied to different vineyard plots. Finally, Section 6 points out the main conclusions and future directions towards new developments and the method's applicability.

\section{Data description}

Data used in this study came from vineyards located in Portugal's north-eastern region, which has some unique features concerning the size, terrain slope, and management practices.

Aerial surveys were performed using the low-cost and light-weight (1380 g) rotarywing UAV DJI Phantom 4 (DJl, Shenzhen, China), which has a maximum flight time of approximately $28 \mathrm{~min}$ per battery and vertical take-off and landing capabilities. It is equipped with a remote controller, a Global Navigation Satellite System (GNSS) receiver, a camera, and a frontal collision avoidance system. Regarding the camera - attached to a 3-axis gimbal that provides stabilization - it has a 12.4 megapixel sensor, which allows acquiring RGB images with a maximum resolution of $4000 \times 3000$ pixels. Autonomous flights were carried out using the Pix4Dcapture app (Pix4D SA, Lausanne, Switzerland) on an Android smartphone.

This study's flights took place during June and July 2017, using a double-grid configuration, at 60-80 $\mathrm{m}$ height, from the UAV take-off position and with an image overlap between $70 \%$ and $80 \%$. Acquired data were processed using Pix4Dmapper Pro (Pix4D SA, Lausanne, Switzerland), which can compute orthophoto mosaics, DSM, and DTM from a dense point cloud. This type of very high-resolution data provides a general overview of the whole vineyard. Furthermore, it enables to associate operations - such as Vls - that allow the enhancement of certain vegetation features by using 
combinations from multiple bands and CSM, which can be computed to obtain surface's objects' heights. The computation of both the photogrammetric and the proposed method was performed by using a laptop equipped with a $2.6 \mathrm{GHz}$ Intel i7-4720HQ CPU, 16GB RAM (DDR3, $1600 \mathrm{MHz}$ ), and a NVidia GeForce GTX 970m (3GB GDDR5 $5000 \mathrm{MHz})$ GPU.

Aerial surveys included three different vineyards, from which 16 plots were used for further evaluation. Figure 1 shows the orthophoto mosaics of the three vineyards used in this study and presents details about the flight characteristics for each vineyard, along with the boundaries of each analysed plot and the areas used for VIs and method's validation. Vineyards $B$ and $C$ are used for commercial purposes, while vineyard $A$ is not. When compared in-field, plots belonging to vineyard $B$ show better management
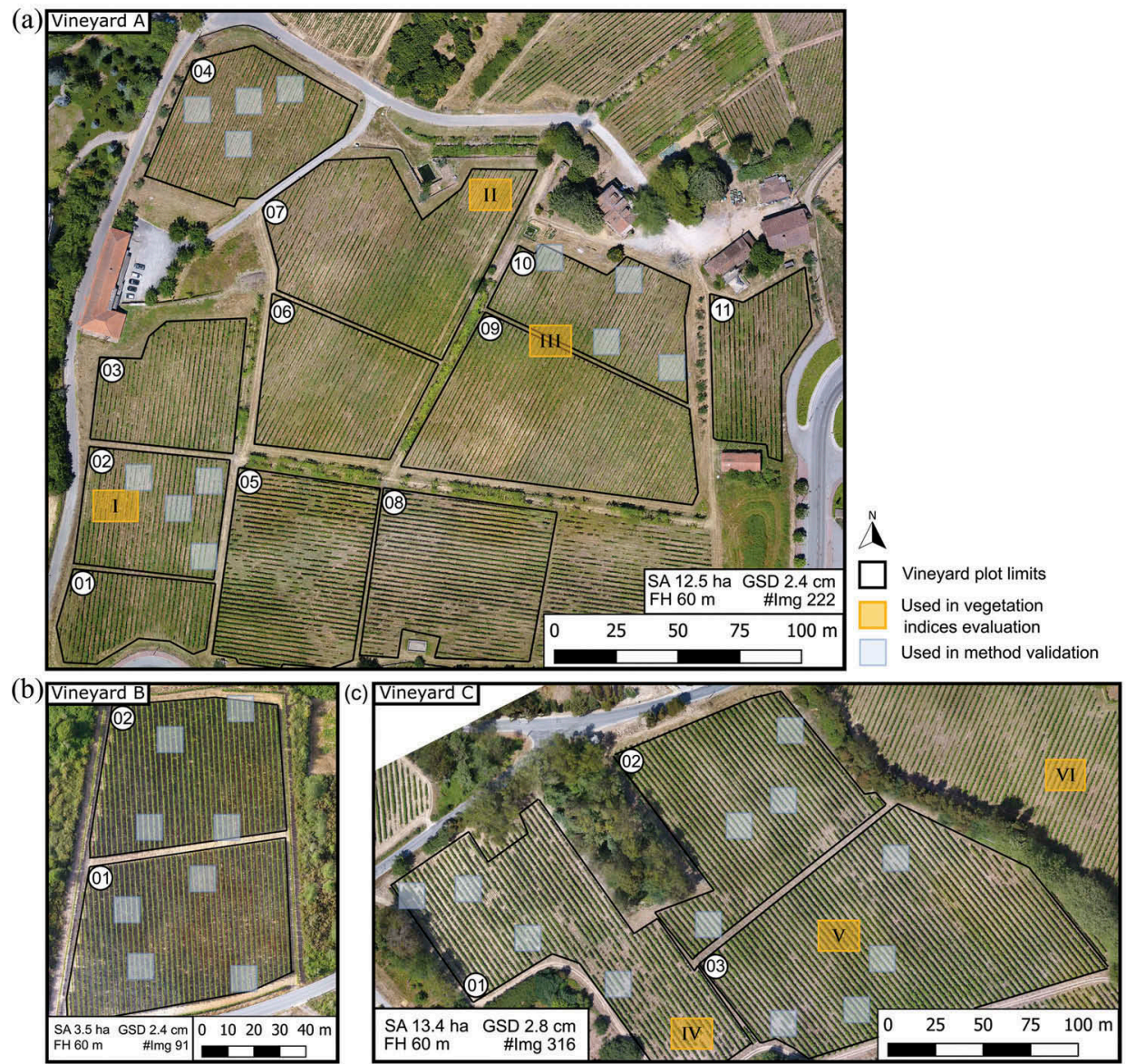

Figure 1. Resulting orthophoto mosaics from the three surveyed vineyard plots used to evaluate the proposed method along with their flight characteristics, surveyed area (SA), flight height (FH), ground sample distance (GSD), and number of acquired images (\#Img). Vineyard $A$ is located at $41^{\circ} 17^{\prime} 08.0^{\prime \prime} \mathrm{N}, 7^{\circ} 44^{\prime} 12.0^{\prime \prime} \mathrm{W}$; vineyard B at $41^{\circ} 17^{\prime} 41.5^{\prime \prime} \mathrm{N}, 7^{\circ} 29^{\prime} 51.3^{\prime \prime} \mathrm{W}$; and Vineyard $\mathrm{C}$ at $41^{\circ} 15^{\prime} 51.5^{\prime \prime} \mathrm{N}$, $8^{\circ} 14^{\prime} 12.1$ "W. The analysed plots are delimited by black lines and areas extracted from the orthophoto mosaics being polygons delimited in yellow (used in vegetation indices) and blue (used in the method's validation). 
practices or are less affected by biotic issues than vineyards $A$ and $C$. The latter has more missing vine plants along the plots. Vineyard $C$ plots have larger areas and are surrounded by trees - that cover part of the rows - at their outer limits. Regarding the analysed plots, 11 plots were from vineyard A, 2 from vineyard B, and 3 from vineyard $C$, as presented in Figure 1.

\section{Vineyard vegetation detection using Vls}

VI behaviour with different vineyard images, vine rows orientation, shadow presence, inter-row vegetation, and missing vine plants was observed and compared. Six different areas within the studied vineyard plots were analysed, as presented in Figure 2.

The evaluation process is composed of the following steps: (1) VIs are computed in each area, producing a greyscale image from the arithmetic operations done on different bands; (2) then, a global threshold is applied on the resulting images to create a binary image, based on Otsu's method (Otsu 1979). This method is capable of automatically threshold a single-band image by dividing its histogram in foreground and background pixels; (3) morphological operations (open and close) are carried out to filter the binary images (small clusters of pixels are removed), thus improving the results obtained from Vls; and (4) lastly, the resulting binary image is compared with a manually segmented image that is used as reference.

Accuracy is computed by comparing the resulting image obtained for each VI by applying the aforementioned steps with its reference image. Results are calculated by analysing the value of each pixel, from which one of the three conditions can be observed: (1) same pixel value in both images ( 0 or 1 ), which is classified as 'exact detection'; (2) a false detection, if the pixel value of the manually segmented image is one and in the resulting image is zero, being classified as 'underdetection'; and (3) classified as 'overdetection' if the situation is opposite to the one described in (2). Based on the bibliographic review, 13 Vls were selected, which are presented in Table 1, and evaluated in this process. From these, only some were directly applied to vineyards.

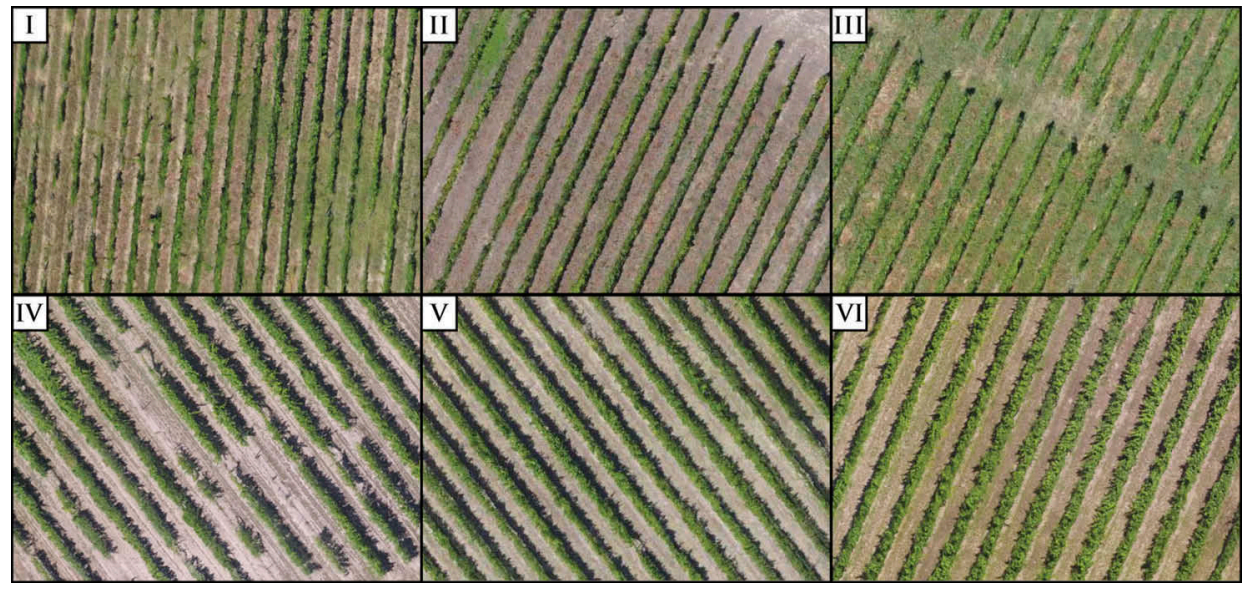

Figure 2. RGB images of the areas used to evaluate VI behaviour (row orientation, shadow presence, inter-row vegetation, and missed plants were considered). 
Table 1. RGB vegetation indices evaluated in the estimation of vineyard vegetation.

\begin{tabular}{|c|c|c|}
\hline Index & Formula & References \\
\hline $\begin{array}{l}\text { Normalized green red } \\
\text { difference index }\end{array}$ & $\mathrm{NGRDI}=\frac{\text { Green }- \text { Red }}{\text { Green }+ \text { Red }}$ & $\begin{array}{l}\text { (Falkowski et al. 2005; Gitelson et al. } \\
\text { 2002; Kawashima and Nakatani 1998; } \\
\text { Tucker 1979) }\end{array}$ \\
\hline $\begin{array}{l}\text { Normalized green blue } \\
\text { difference index }\end{array}$ & $\mathrm{NGBDI}=\frac{\text { Green }- \text { Blue }}{\text { Green }+ \text { Blue }}$ & (Kawashima and Nakatani 1998) \\
\hline $\begin{array}{l}\text { Modified normalized green } \\
\text { red difference index }\end{array}$ & MNGRDI $=\frac{\operatorname{Green}^{2}-\operatorname{Red}^{2}}{G_{\text {reen }}^{2}+\operatorname{Red}^{2}}$ & (Bendig et al. 2015) \\
\hline $\begin{array}{l}\text { Red green blue vegetation } \\
\text { index }\end{array}$ & RGBVI $=\frac{\text { Green }^{2}-(\text { Blue } \times \text { Red })}{\text { Green }^{2}+(\text { Blue } \times \text { Red })}$ & (Bendig et al. 2015) \\
\hline Blue/green pigment index & $\mathrm{BGVI}=\frac{\text { Blue }}{\text { Green }}$ & (P. J. Zarco-Tejada et al. 2005) \\
\hline Blue/red pigment index & BRVI $=\frac{\text { Blue }}{\text { Red }}$ & (P. J. Zarco-Tejada et al. 2005) \\
\hline $\begin{array}{l}\text { Excess green } \\
\text { Woebbecke index }\end{array}$ & $\begin{array}{l}\text { ExG }=2 g_{n}-r_{n}-b_{n} \\
W I=\frac{g_{n}-b_{n}}{r_{n}-g_{n}}\end{array}$ & $\begin{array}{l}\text { (Woebbecke et al. 1995) } \\
\text { (Woebbecke et al. 1995) }\end{array}$ \\
\hline Vegetation index green & VARIg $=\frac{{ }_{n} \text { Green }- \text { Red }}{\text { Green }+ \text { Red }- \text { Blue }}$ & (Gitelson et al. 2002) \\
\hline Green leaf index & $\mathrm{GLI}=\frac{2 \text { Green }- \text { Red }- \text { Blue }}{2 \text { Green }+ \text { Red }- \text { Blue }}$ & (Gobron et al. 2000; Hunt et al. 2013) \\
\hline $\begin{array}{l}\text { Triangular greenness index } \\
\text { 2G_RGi }\end{array}$ & $\begin{array}{l}\mathrm{TGI}=\mathrm{Green}-0.39 \times \text { Red }-0.61 \times \text { Blue } \\
\text { 2G_RGi }=2 \text { Green }-(\text { Red }+ \text { Blue })\end{array}$ & $\begin{array}{l}\text { (Hunt et al. 2013) } \\
\text { (Richardson et al. 2007) }\end{array}$ \\
\hline Green percentage index & $\mathrm{G} \%=\frac{\text { Green }}{(\text { Red }+ \text { Green }+ \text { Blue })}$ & (Richardson et al. 2007) \\
\hline
\end{tabular}

An overall average result of $87 \%$ of vineyard vegetation exact detection was reached. The only exception was the Woebbecke Index (WI) that was very inconsistent amongst the tested areas (from $49 \%$ to $89 \%$ exact detection), as presented in Table 2. It is worth to note that many VIs had over $90 \%$ accuracy when applied to the different areas.

G\% with 91.9\%, GLI with 91.8\%, RGBVI with 91.6\%, and ExG and NGBDI, both with $91.4 \%$, are the VIs with the highest average accuracy. Moreover, while NGBDI reached $4.6 \%$ of overdetection, the remaining had lower values - around $2 \%$. These five VIs were compared to select the most suitable for vineyard's vegetation detection. Figure 3 presents the evaluation regarding the areas where VIs presented the same value. As depicted, the five Vls have an overlap of $94 \%$ for the six tested areas, which makes their performance very similar. However, G\% has a slightly higher performance and was therefore selected for this study.

Figure 4 shows the agreement between the automatic threshold value obtained from the Otsu's method and a selected fixed threshold value. The obtained results are in line with the mean values given from the Otsu's method in the six evaluated areas and the overall detection percentage assumes only one maximum value, proving the suitability of the Otsu's method to automatically estimate a threshold value.

\section{Proposed method for vineyard analysis}

This section presents the proposed method to identify vineyard vegetation, distinguishing it from non-vineyard features that can be present in a vineyard plot. The main challenge when regarding vineyard vegetation monitoring is related with the similar reflectance that other types of vegetation can present, which is especially noticeable in common RGB imagery and less noticeable in NIR or hyperspectral imagery. Therefore, by considering the usual vineyards' row structure and its regularity, the method explores 


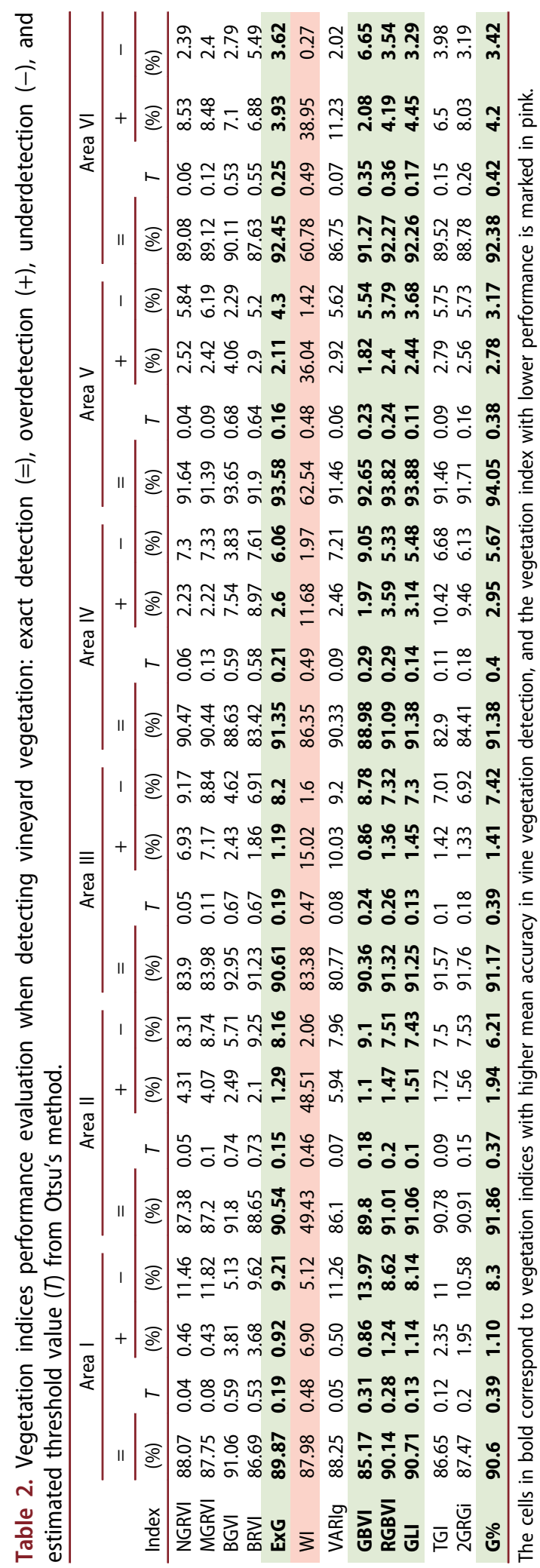




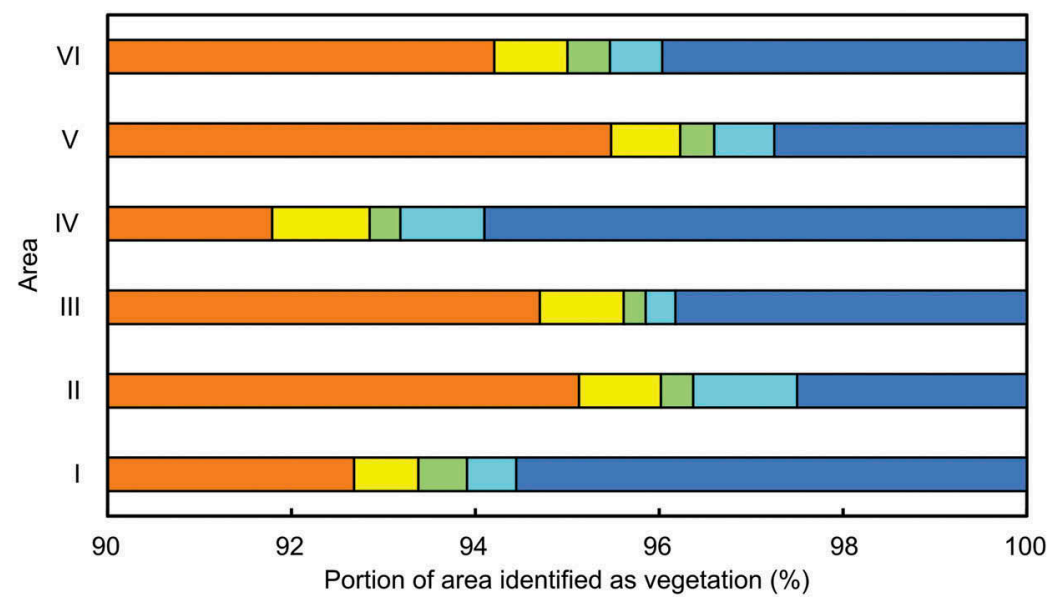

\begin{tabular}{|l|c|c|c|c|c|c|}
\hline $\begin{array}{c}\text { Identified } \\
\text { vegetation (\%) }\end{array}$ & Area I & Area II & Area III & Area IV & Area V & Area VI \\
\hline$\square \ln 5$ indices & 92.68 & 95.13 & 94.70 & 91.79 & 95.48 & 94.21 \\
\hline$\square \ln 4$ indices & 0.70 & 0.89 & 0.91 & 1.06 & 0.75 & 0.79 \\
\hline$\square \ln 3$ indices & 0.53 & 0.35 & 0.24 & 0.34 & 0.37 & 0.46 \\
\hline$\square \ln 2$ indices & 0.54 & 1.13 & 0.32 & 0.91 & 0.65 & 0.57 \\
\hline$\square \ln 1$ index & 5.56 & 2.50 & 3.82 & 5.90 & 2.75 & 3.97 \\
\hline
\end{tabular}

Figure 3. Percentage of common pixels to the five-selected VIs in the test areas.
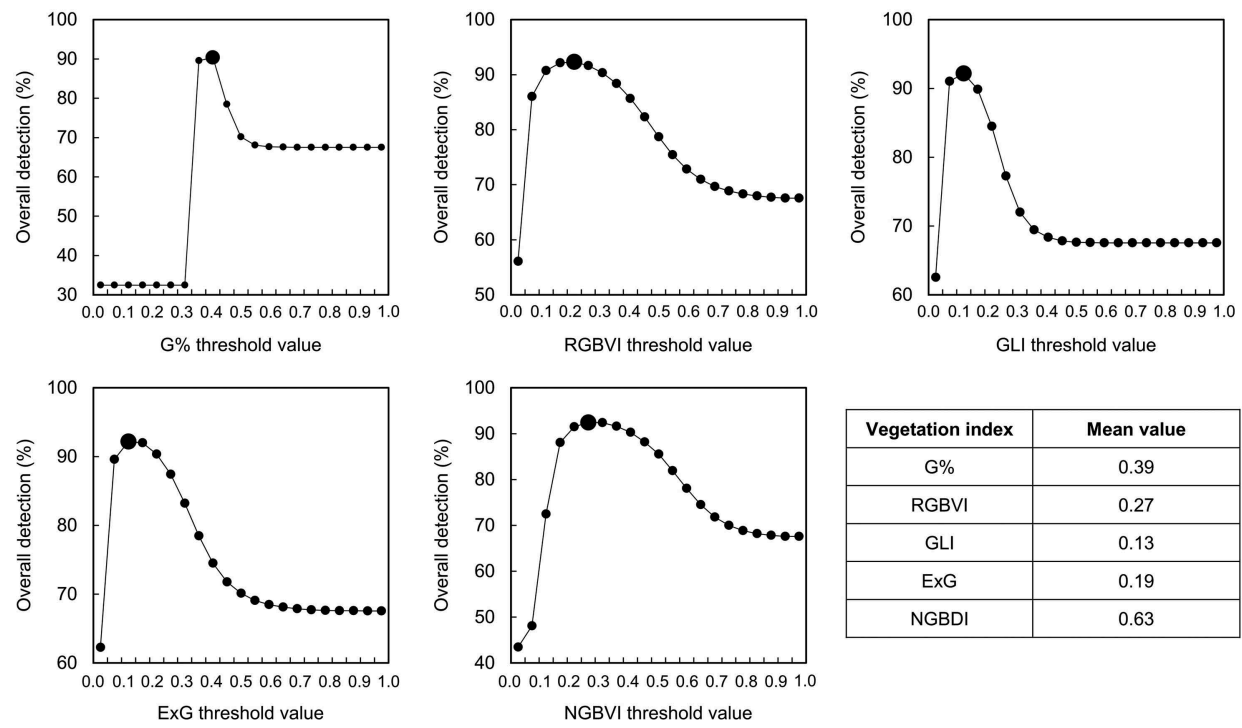

\begin{tabular}{|c|c|}
\hline Vegetation index & Mean value \\
\hline G\% & 0.39 \\
\hline RGBVI & 0.27 \\
\hline GLI & 0.13 \\
\hline ExG & 0.19 \\
\hline NGBDI & 0.63 \\
\hline
\end{tabular}

Figure 4. Vine vegetation detection accuracy based on the threshold values for the top five vegetation indices in area III. It is also presented a table with the averaged results.

the usage of the different outcomes provided by photogrammetric processing of UAS imagery in combination with image processing techniques that namely use elevation data and orthophoto mosaic. This enables the classification of vine vegetation within a given vineyard plot and distinguish it from vegetation cover, shadows, and bare soil. 
Moreover, the proposed method is also capable to estimate potential missing vine plants. As inputs, the UAS-based photogrammetric outcomes are used. Feature extraction from a given vineyard plot is achieved by masking non-vine vegetation.

Figure 5 presents the proposed method's operation sequences. There are three distinct steps composing it: (1) vegetation extraction and pixel clustering; (2) vine rows reconstruction, by means of analysing each formed pixel cluster retrieved in step 1 ; and (3) vineyard parameters extraction - vine rows, vineyard vegetation, and potential missing vines. Each step plays an essential role in the process of vineyard vegetation extraction. All are further detailed in the next subsections. The notation used in this section is explained in Table 3.

\subsection{Step 1: vegetation extraction and pixel clustering}

Method's step 1 aims to extract vine-related pixels from the aerial high-resolution images of a given vineyard plot, which defines the polygon $\mathbf{P}$ (Figure 6(f)). As such, data that do not represent vine vegetation, such as soil, grass, and possible shadowing effects caused by vine canopies, trees, and buildings, is discarded. To accurately complete this step, both orthophoto mosaic (Figure 6(a)) and elevation data (Figure 6(b,c)) are used. The former is used to compute the VI (Figure 6(d)). Assuming that in the produced orthophoto mosaic, vegetation presents higher reflectance values than nonvegetation areas, a threshold operation can be applied to separate both. The computed VI is used to create a binary image produced using Otsu's method (Otsu 1979), as presented in Equation (1), where V (Figure 6(g)) represents the computed binary image resulting from the Otsu's method application, VI represents the image produced by the VI computation, and $T$ represents the defined threshold from Otsu's method. For each $(i, j)$ pixel position in the image, $i$ represents the line number and $j$ represents the
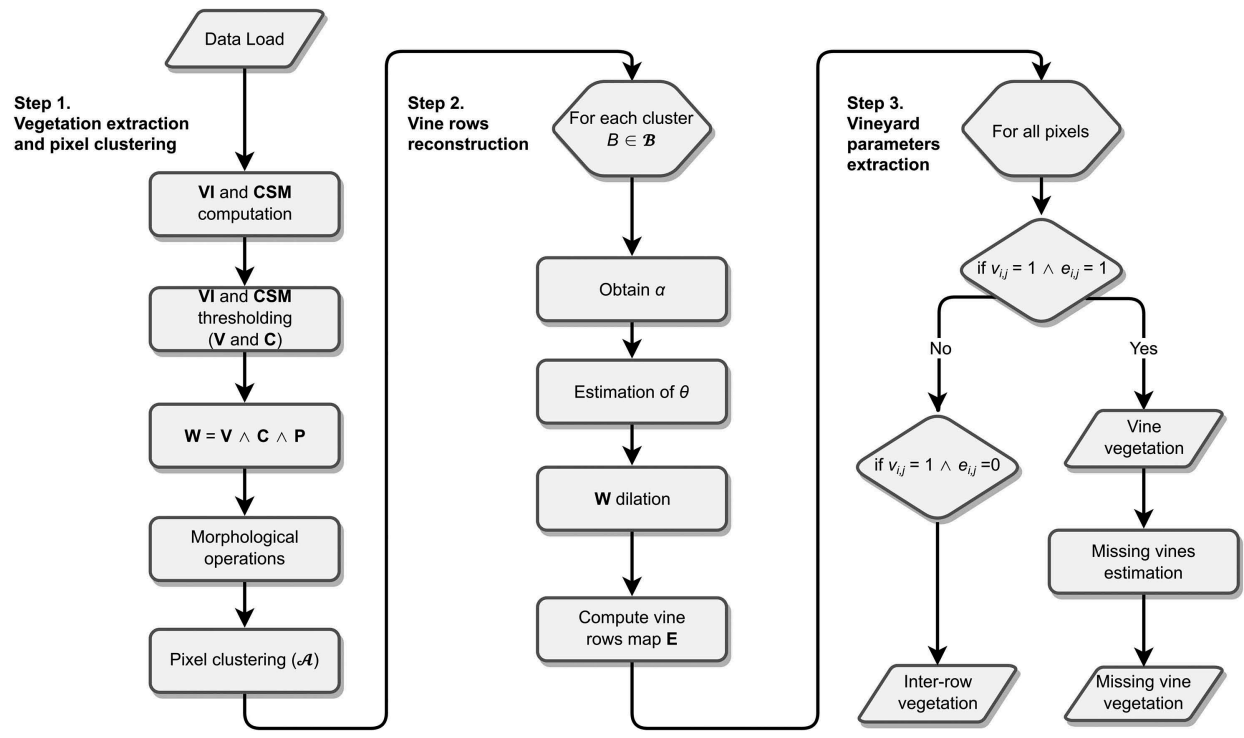

Figure 5. Proposed method's operation general flow chart. 
Table 3. Notation table.

\begin{tabular}{|c|c|}
\hline Notation & Meaning \\
\hline $\mathbf{P}$ & Binary image of the polygon of the plot to be analysed \\
\hline VI & Single-band image obtained from vegetation index computation \\
\hline$T$ & Threshold value obtained from Otsu's method application \\
\hline $\mathbf{V}$ & Binary image resultant from $\mathbf{V I}$ thresholding step \\
\hline CSM & Single-band image obtained from subtraction of the DTM to the DSM computation \\
\hline$h_{\max }$ & Maximum height range used for CSM thresholding \\
\hline$h_{\min }$ & Minimum height range used for CSM thresholding \\
\hline C & Binary image resultant from CSM thresholding according to $h_{\min }$ and $h_{\max }$ \\
\hline $\mathbf{W}$ & Binary image resultant from the conjunction of $\mathbf{V}, \mathbf{C}$, and $\mathbf{P}$ \\
\hline$B$ & Group of interconnected pixels forming a cluster resultant from pixel clustering \\
\hline $\mathcal{B}$ & Set of all detected clusters B in $\mathbf{W}$ \\
\hline$a$ & Orientation angle of the cluster $\mathrm{B}$ \\
\hline$\theta$ & Mean orientation all $a$ values from the set of clusters $\mathcal{B}$ \\
\hline $\mathbf{F}_{\theta}$ & Structuring element used to dilate $\mathbf{W}$, forming $\mathbf{E}$. It is constituted by a line with orientation $\theta$ \\
\hline $\mathbf{E}$ & Binary image resultant after dilation of $\mathbf{W}$ \\
\hline$D$ & Group of interconnected pixels forming a clusters resultant from the pixel clustering of $\mathbf{E}$ \\
\hline $\mathcal{D}$ & Set of all detected clusters in $\mathbf{E}$ \\
\hline $\mathbf{U}$ & Binary image containing estimated inter-row vegetation \\
\hline $\mathbf{L}$ & Binary image with all pixels detected in $\mathbf{V}$ present in $\mathbf{E}$ \\
\hline$\overline{\mathrm{L}}$ & Complement of $\mathbf{L}$ \\
\hline$S_{\text {centre }}$ & Line segment that intersects each cluster's $(D)$ centroid, ends in its extremities, and has its orientation \\
\hline $\mathbf{S}$ & Binary image contained all detected $\mathrm{S}_{\text {centre }}$ elements \\
\hline $\mathbf{F}_{r}$ & Structuring element used to dilate $\mathbf{G}$, forming $\mathbf{Q}$. It has a disk shape element with radius $r$ \\
\hline G & $\begin{array}{l}\text { Binary image produced after intersection of all } s_{i, j} \text { pixels with } \bar{l}_{i, j} \text {, representing vine row areas with } \\
\text { potential missing vines }\end{array}$ \\
\hline Q & Binary image produced after $\mathbf{G}$ dilation, representing vine rows areas with potential missing vines \\
\hline $\mathbf{K}$ & Property intended be used to calculate its area, which can assume the value of the binary images $\mathbf{E}, \mathbf{L}, \mathbf{Q}$ \\
\hline$A$ & $\begin{array}{l}\text { Area of a given property to calculate } \mathbf{K} \text {, which is the sum of all pixel values ( } 0 \text { or } 1 \text { ) of a binary image with } \\
m \times n \text { size }\end{array}$ \\
\hline
\end{tabular}

column number. In this way, $v_{i, j}$ represents the matrix $\mathbf{V}$ entry for the position $(i, j)$. The same notation is used in the remaining equations.

$$
v_{i, j}=\left\{\begin{array}{l}
1, v i_{i, j} \geq T \\
0, v i_{i, j}<T
\end{array}\right.
$$

Next, CSM (Figure 6(e)) is computed using elevation data, as shown in Equation (2) (Holman et al. 2016; Matese, Gennaro, and Berton 2016). Each pixel contains a value $h$ that corresponds to the height of objects above ground: values close to zero represent the ground. This operation removes the field's topography.

$$
\mathrm{CSM}=\mathrm{DSM}-\mathrm{DTM}
$$

In the same way as $\mathbf{V}$, the computed CSM has a thresholding operation, as represented in Equation (3), where each height value $(h)$ is analysed according to a height range (from $h_{\min }$ to $h_{\max }$ ), producing a binary image C (Figure 6(h)), only containing pixels within the values defined for the height range. This process enables a CSM's pixel-wise filtering to discard pixels other than vineyard's vegetation. Knowledge of the analysed areas allowed the selection of $h$ values ranging from 0.5 to $2 \mathrm{~m}$, thus removing possible data other than vineyard's vegetation. However, height range may depend on both the vineyard's architecture and the management practices used. 


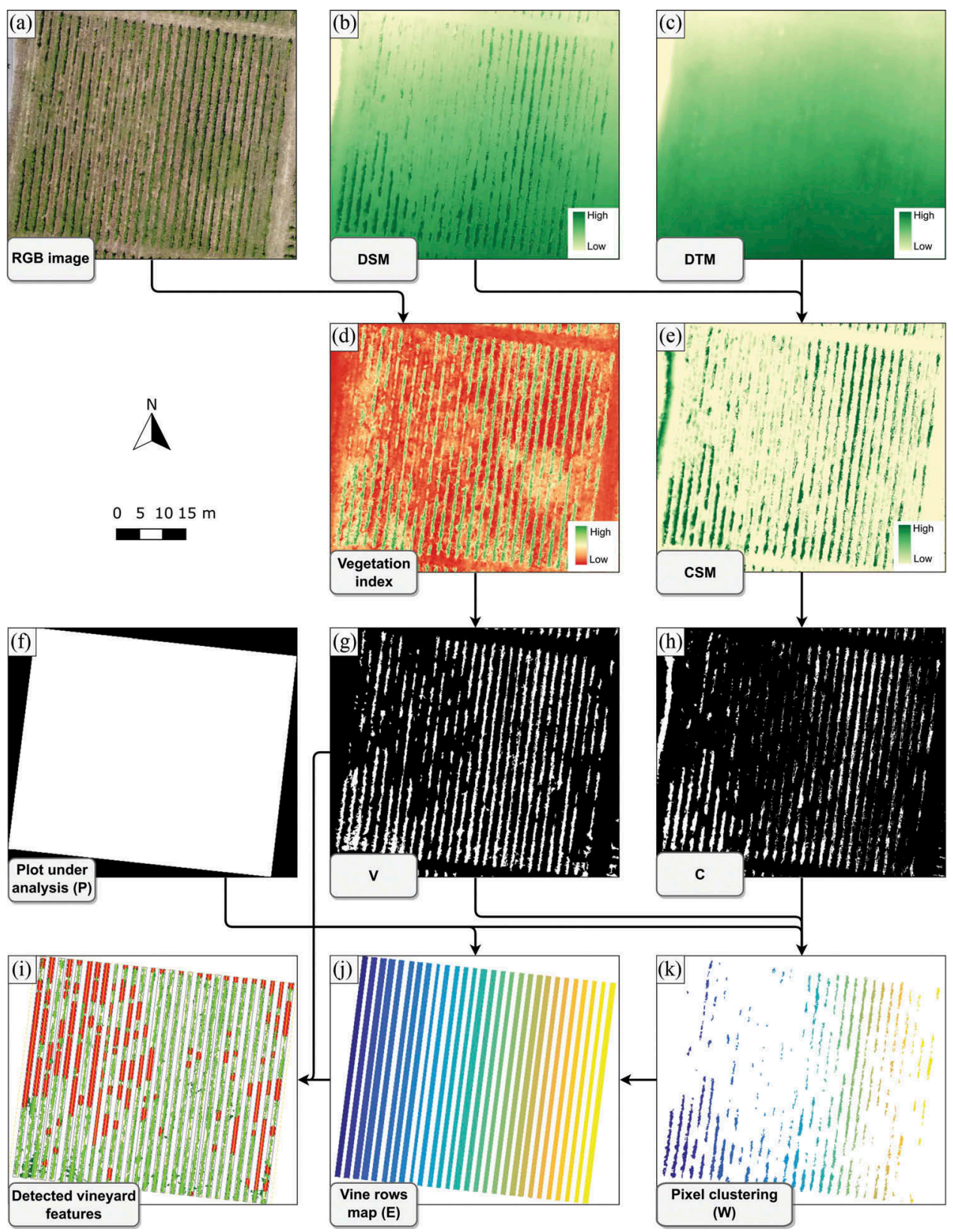

Figure 6. Extracted parameters resulting from the proposed method's step 3. Green colours represent detected vegetation - light green corresponds to vine row vegetation and dark green to inter-row vegetation; red represents the estimated missing vegetation; yellow represents the row centre; and grey the estimated vine rows boundaries.

$$
c_{i, j}=\left\{\begin{array}{l}
1, h_{\min } \leq \operatorname{csm}_{\mathrm{i}, \mathrm{j}} \leq h_{\max } \\
0, \text { otherwise }
\end{array} .\right.
$$

As shown in the RGB image presented in Figure 7(a) and in the false colour image, that results from applying G\% VI (Figure 7(b)), part of the inter-row vegetation has 
(a)

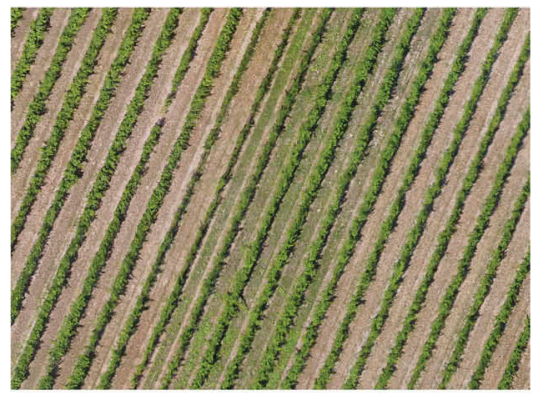

(c)

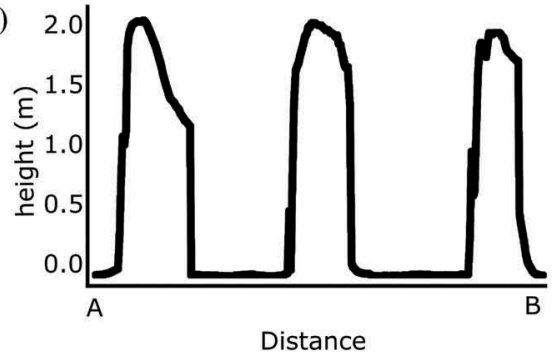

(b)

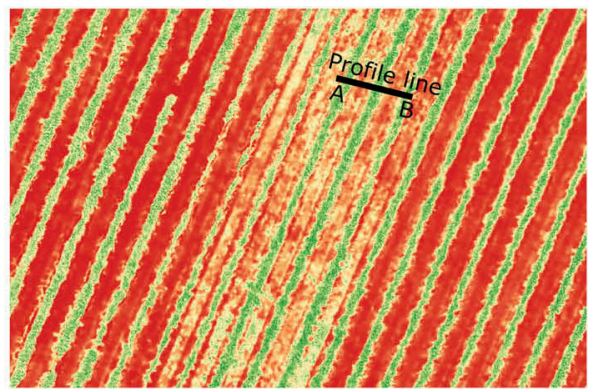

Vegetation index (b)

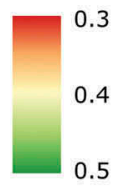

$\begin{array}{llllll}0 & 5 & 10 & 15 & 20 & \mathrm{~m}\end{array}$

Figure 7. Different UAS-based outcomes from part of a vineyard plot: (a) RGB image; (b) corresponding false colour image from the green percentage index computation; and (c) CSM line profile from the line traced upon three vine rows.

almost the same reflectance value of some vine canopies, which is not verified in the CSM computation, presented in Figure 7(c).

The method's main steps are summarized in Figure 8, where plot 02 from vineyard A is used to illustrate its application, from the input data to the final extracted parameters.

Figure 9 presents a fraction of a vineyard plot where the superimposed lines are related to the thresholded G\% - in yellow - (V) and CSM above $0.5 \mathrm{~m}$ and below $2 \mathrm{~m} \mathrm{-}$ in red (C). The detection of inter-row vegetation is noticeable in $\mathbf{V}$. However, it is accurate in the row's vegetation. On the other hand, shadow detection is also considered in the $\mathbf{C}$ threshold but not in $\mathbf{V}$.

By merging both types of data, it is possible to obtain areas where only pixels considered as vegetation and with a certain height are present, thus removing vegetation cover that could also be identified as vine vegetation, which would lead to erroneous classification of vine rows. In this way, the conjunction of the binary images produced after thresholding ( $\mathbf{V}$ and $\mathbf{C})$ is used to create a new binary mask image $(\mathbf{W})$ (Figure $8(\mathrm{k})$ ), according to Equation (4), where $\mathbf{P}$ is also considered to discard pixels outside the area under analysis.

$$
w_{i, j}=\left\{\begin{array}{l}
1, \text { if } v_{i, j}=1 \wedge c_{i, j}=1 \wedge p_{i, j}=1 \\
0, \text { otherwise }
\end{array} .\right.
$$

The resulting binary image $(\mathbf{W})$ is submitted to a sequence of morphological operations (open, close, and removal of small objects) to remove outliers and improve the detection accuracy. This step can evaluate different properties from each generated group of interconnected pixels $B \in \mathcal{B}$, where $\mathcal{B}$ represents all the detected clusters at the plot 


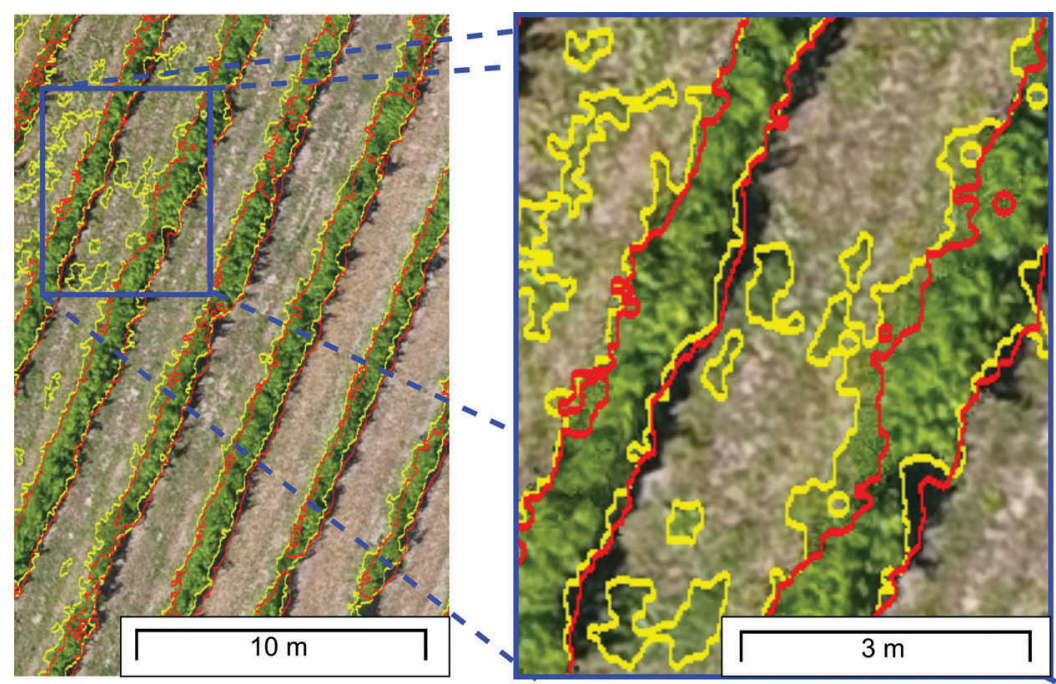

Figure 8. Method processing steps applied to the plot 02 from vineyard A, some images are in a false colour representation for better interpretation.

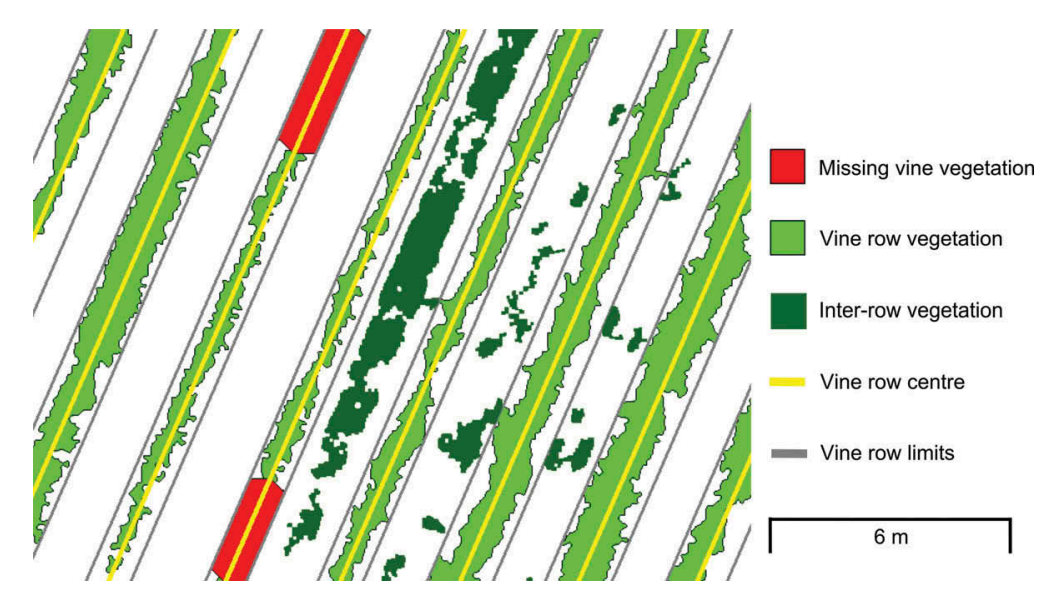

Figure 9. Visual interpretation of both the thresholding and the masking processes: vegetation index represented in yellow and the canopy height model in red.

level. Resulting clusters are areas where vine canopies are present. At this stage, each vine row is not connected and therefore a reconstructive process takes place to join the unconnected clusters into row shapes.

\subsection{Step 2: vine rows reconstruction}

Depending on the vineyards' management practices and on the acquired data resolution, clusters of pixels obtained in the proposed method's step 1 do not represent complete vine rows, requiring a reconstruction process. Therefore, the mean plot orientation $\theta$ is estimated based on the dominant angle of all detected clusters from the set of clusters $\mathcal{B}$. This angle $(\theta)$ is obtained by the orientation $a$ of each detected 
cluster, which is computed based on the angle between the $x$-axis and the major axis of the ellipse containing the same second-moments as $B$. $\theta$ assumes the mean value of all $a \in \mathcal{B}$. Then, clusters are submitted to a dilation process, $\phi$, using a linear structuring element $\mathbf{F}_{\theta}$ with one-pixel width and orientation $\theta$, obtaining $\mathbf{E}$, which depicts the vine rows map of the plot under analysis, as represented in Equation (5) (Figure 8(j)). This forms a new set of clusters $\mathcal{D}$, where $D$ represents a single vine row.

$$
e_{i, j}=\phi \mathbf{F}_{\theta}\left(w_{i, j}\right) \text {, where } e_{i, j} \wedge p_{i, j}=1 \text {. }
$$

By applying this procedure, previously unconnected clusters begin to form a set of clusters representing the connection of clusters in each row, therefore enabling vine rows reconstruction.

\subsection{Step 3: vineyard parameters extraction}

Method's step 3 relies on the final extraction of vineyard-related information, namely by estimating vine rows, vineyard vegetation, and areas with missing vine plants (Figure 8(i)). The resulting vine rows estimation image $(\mathbf{W})$ - obtained after the proposed method's step 2 - enables to estimate the number of rows and their occupation area present in $\mathbf{P}$. After estimating rows, the mask with vegetation $(\mathbf{V})$ is used to detect vine's vegetation, where all pixels present in $\mathcal{B}$ and contained in $\mathcal{D}$ form $\mathbf{L}$, which represents the vine vegetation.

Vegetation that lies outside vine rows area and that is considered in $\mathcal{B}$ is classified as inter-row vegetation $(\mathbf{U})$. Areas with potential missing vine plants are predicted by matching the estimated vine rows mask central lines $\mathbf{S}$ with the complement of the estimated vine vegetation $\overline{\mathbf{L}}$, forming a new binary image $\mathbf{G}$. $\mathbf{S}$ is constituted by $S_{\text {centre }}$ which is a line segment that intersects each cluster's (D) centroid and ends at its extremities and has its orientation. However, detecting possible missing vine plants is typically a more complex problem, since, in many cases, adjacent vines tend to cover the empty space of the missing vine canopy, making the estimation more complicate. Next, the clusters pass through a process of image dilation, represented in Equation (6), to compute a representative map of the detected areas, $\mathbf{Q}$. However, this time, $\mathbf{F}$ is a disk-shaped structuring element whose radius $r$ is half of the mean value of all cluster's width $(\mathcal{D})$.

$$
q_{i, j}=\phi \mathbf{F}_{r}\left(g_{i, j}\right)
$$

The area $A$ of each estimated output can be calculated by Equation (7), which represents the sum of all pixels contained (matrix with $m$ lines and $n$ columns) in the property to calculate $\mathbf{K}$ (vine rows area, vine vegetation, potential missing vine plants, and inter-row vegetation), multiplied by the squared GSD value.

$$
A=\left(\sum_{m}^{i=1} \sum_{n}^{j=1} k_{i . j}\right) \mathrm{GSD}^{2} .
$$

Figure 6 presents the detected vegetation, potential missing vine plants and the estimated vine rows area. The method's outputs are an accurate and quick way to provide vineyard status information in a PV context, to help viticulturists in their vineyard management activities. 


\section{Results and discussion}

For validation purposes, the proposed method was applied to 16 plots from three different vineyards presented in Section 2 (Figure 1). As an accurate manual segmentation of the vineyard vegetation present in all the selected plots is a highly laborious and time-consuming task, small fractions of eight plots - A.02, A.04, A.10, B.01, B.02, C.01, C.02, and C.03 were extracted. This allowed a more precise and quicker process to create precise manual segmented images. The aforementioned fractions - four per plot, each with an approximated area of $100 \mathrm{~m}^{2}(10 \mathrm{~m} \times 10 \mathrm{~m})$ - were selected assuring diversity in terms of rates of missing vine plants, rows orientation, and inter-row vegetation.

\subsection{Proposed method validation}

Regarding vine rows estimation, different parameters were evaluated: (1) good detection - the row was detected with a high overlap when compared with its real position; (2) missed detection - the row was not detected; (3) extra detection - wrongly detected vine row; (4) overdetection - the row was classified in multiple vine rows; (5) underdetection - multiple vine rows classified as one row; (6) larger detection - row is larger than its actual size; and (7) smaller detection - vine row is smaller than its actual size. The proposed method validation occurred by using the extracted vineyard fractions and comparing the obtained results with the manual segmentation.

As presented in Table 4, the proposed method achieved a good accuracy in vine rows estimation. Correct row detection was always greater than $90 \%$, with $93.4 \%$ mean value. Moreover, the method could detect successfully all the vine rows, of 353 analysed. On the analysed fractions, missed, extra, over, or underdetection cases were not found. Regarding the detected vine rows, 19 were not correctly estimated, and from those, $2.67 \%$ were classified as 'larger detection' and $2.88 \%$ as 'smaller detection.' Moreover, the percentage of real vineyard vegetation contained in the estimated vine rows area was calculated to further validate vine rows estimation achieving a mean value of $99.7 \%$. This was achieved by intercepting the manual segmented vineyard fractions with the estimated vine rows.

Finally, vine vegetation extracted by applying the proposed method also underwent a validation process that consisted in comparing it with the manual segmented images. Figure 10(a) presents these results. The method achieved a $94.10 \%$ mean percentage of

Table 4. Vine row detection accuracy in eight different vineyard plots, with the number of rows analysed per plot and percentage of detected vineyard vegetation contained in the plot's estimated vine rows.

\begin{tabular}{|c|c|c|c|c|c|c|c|c|c|}
\hline \multirow[b]{2}{*}{$\begin{array}{l}\text { Plot } \\
\text { no. }\end{array}$} & \multirow[b]{2}{*}{$\begin{array}{c}\text { Number of } \\
\text { rows }\end{array}$} & \multirow[b]{2}{*}{$\begin{array}{l}\text { Detected vegetation } \\
\text { portion (\%) }\end{array}$} & \multicolumn{7}{|c|}{ Type of vine rows detection (\%) } \\
\hline & & & $\begin{array}{c}1 . \\
\text { Good }\end{array}$ & $\begin{array}{c}2 . \\
\text { Missed }\end{array}$ & $\begin{array}{c}3 . \\
\text { Extra }\end{array}$ & $\begin{array}{l}4 . \\
\text { Over }\end{array}$ & $\begin{array}{l}5 . \\
\text { Under }\end{array}$ & $\begin{array}{c}6 . \\
\text { Larger }\end{array}$ & $\begin{array}{c}7 . \\
\text { Smaller }\end{array}$ \\
\hline A.02 & 28 & 99.78 & 92.86 & - & - & - & - & 3.57 & 3.57 \\
\hline A. 04 & 34 & 99.97 & 91.18 & - & - & - & - & 5.88 & 2.94 \\
\hline A. 10 & 45 & 99.40 & 95.56 & - & - & - & - & - & 4.44 \\
\hline B. 01 & 43 & 99.50 & 97.50 & - & - & - & - & 2.50 & - \\
\hline B.02 & 37 & 99.78 & 91.89 & - & - & - & - & 2.70 & 5.41 \\
\hline C.01 & 75 & 99.55 & 97.30 & - & - & - & - & 1.35 & 1.35 \\
\hline C.02 & 53 & 99.87 & 92.59 & - & - & - & - & 3.70 & 3.70 \\
\hline C.03 & 60 & 99.93 & 96.72 & - & - & - & - & 1.64 & 1.64 \\
\hline \multicolumn{2}{|c|}{ Mean detection (\%) } & 99.72 & 94.45 & - & - & - & - & 2.67 & 2.88 \\
\hline
\end{tabular}



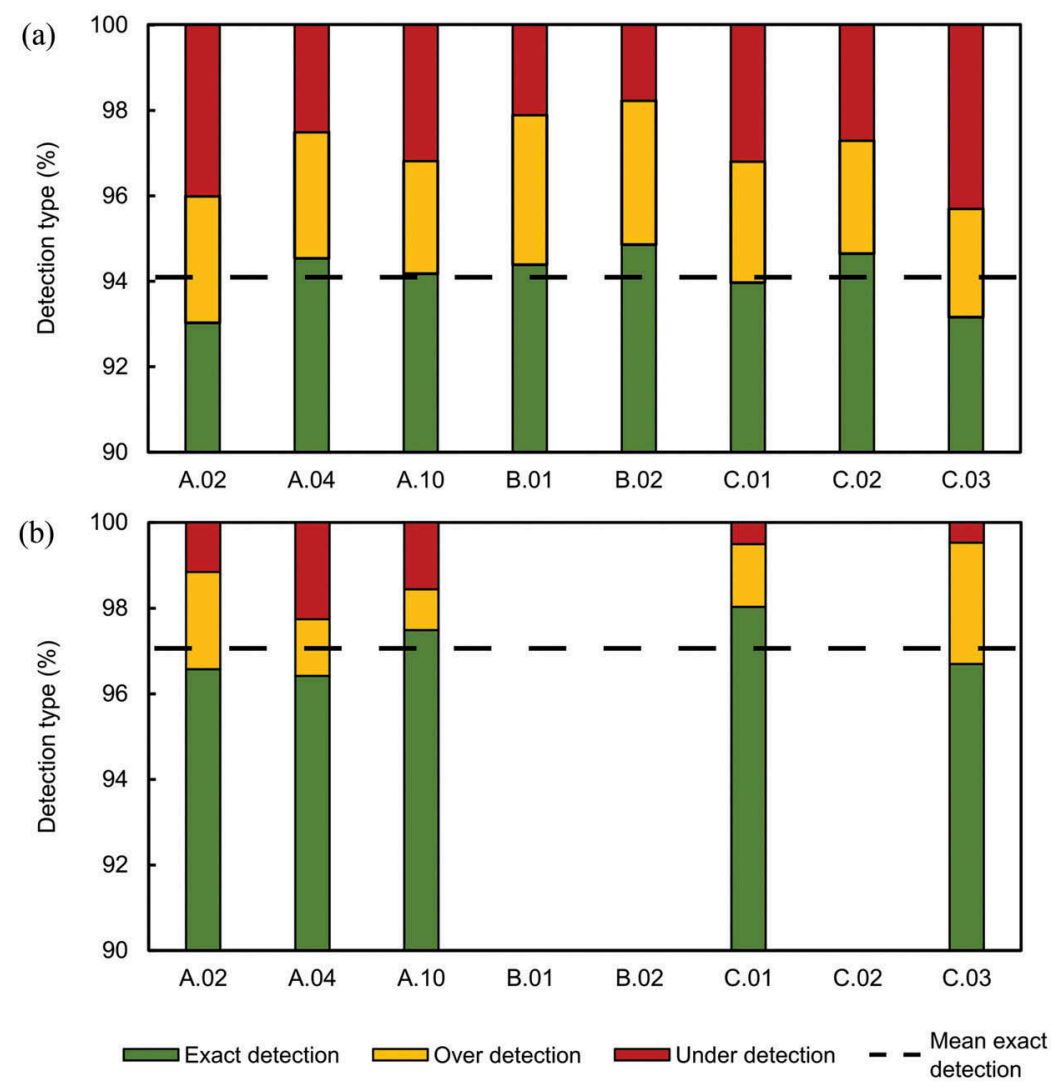

Figure 10. Results from validation of the vine vegetation extraction process (a) and potential missing vine vegetation process (b).

exact vegetation detection, a mean value of $2.93 \%$ regarding overclassification, and 2.97\% of underclassification. Differences between plots' fractions were not meaningful. Indeed, even those with a higher rate of missing vines did not influence the vegetation extraction process. In what regards the validation of missing vegetation estimation, the process was the same as that applied to vegetation estimation. However, only the fractions that have missing vegetation were evaluated. Thus, all plot fractions from vineyard $B$, as well as those from plot 02 from vineyard $C$, were discarded, as they have low rates of missing vegetation. Results achieved a mean value of $97.04 \%$ in exact classification of missing vegetation, as shown in Figure 10(b).

Figure 11 shows only a fraction of the detected vine vegetation, its manual segmented image, and the comparison between both. Most of the non-detected vegetation lies in the vine plants' borders. In vineyard B plots' fractions, variations are less noticeable than in the other vineyards' fractions. This is due to fewer regions with missing vine vegetation in this vineyard. In vineyards $A$ and $C$, there are cases where the presence of shadows and grass in the row is also considered in the estimation of vine vegetation.

These results are satisfactory, since the method proved to be able to accurately detect vine rows with vegetation in almost all scenarios: present inside the estimated vine rows $(99.72 \%)$; to exactly estimate the actual vine vegetation (94.10\%); with a low percentage 


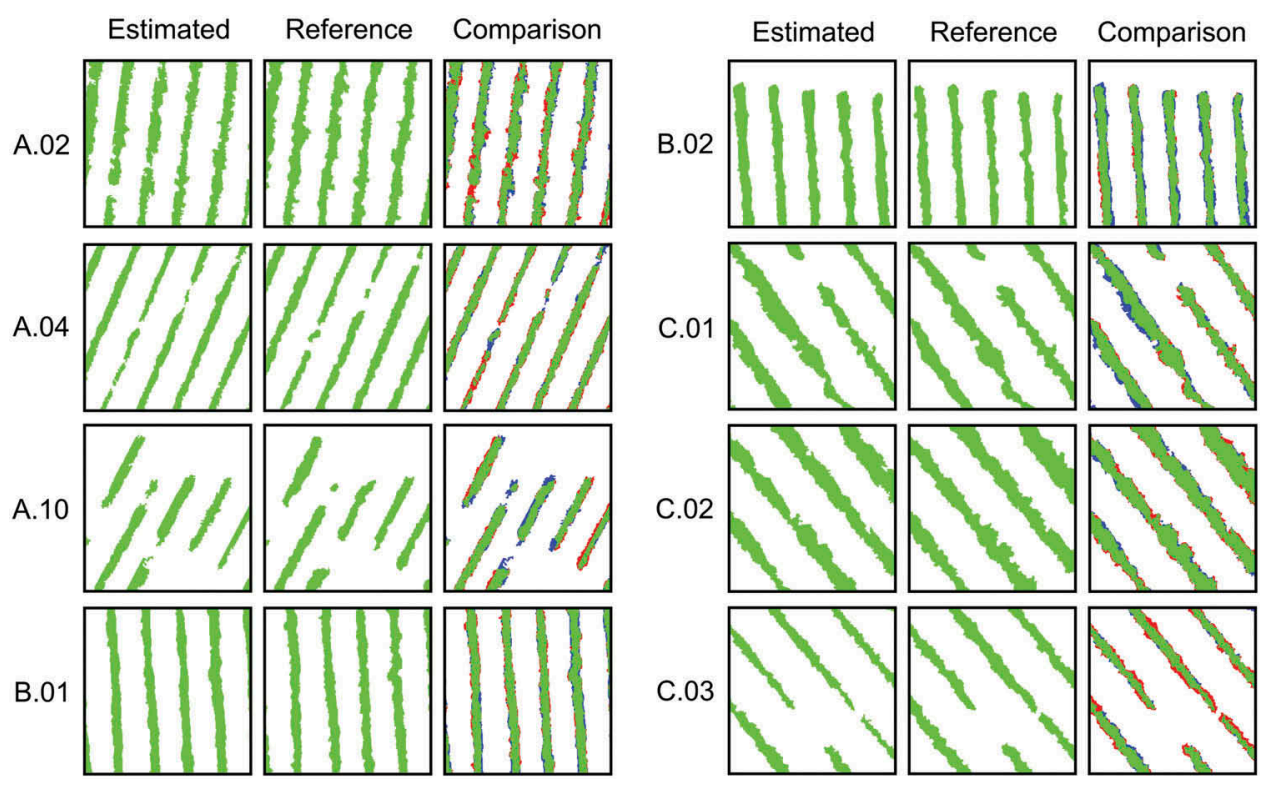

Figure 11. Comparison between the estimated vine vegetation with manually segmented plot fractions. Represented in green are exact classifications, in blue overclassifications, and in red underclassifications.

of underdetection of vegetation (2.97\%); and missing vine vegetation also achieved a good accuracy (97.04\%). The various parameters automatically extracted by applying the proposed method support the generation of accurate vineyard maps and vine rowsrelated properties, such as percentage of vineyard vegetation, missing vines, and interrow vegetation. This proves that the proposed method is useful in PV management and in its decision-making tasks. Furthermore, obtained results are in line with those of previous works (Comba et al. 2015; Nolan et al. 2015), which made use of different image acquisition sensors (NIR) - more expensive when compared with the sensors used in this study - to obtain imagery data.

\subsection{Proposed method application}

The proposed method was applied to 16 plots from vineyards A, B, and C. In all plots, the following parameters were extracted: vine rows estimation, vine vegetation, and missing vines plants estimation. Figure 12 presents an overall view of the evaluated plots. In vineyard $A$, vine rows occupation area ranged from $40 \%$ to $55 \%$; in vineyard $B$ from $37 \%$ to $49 \%$; and in vineyard C, from $53 \%$ to $61 \%$. As expected, a higher percentage of missing vine vegetation was found in vineyard A (plot A.01 to A.11), with an average of $28 \%$ of missing vineyard vegetation. On the other hand, vineyard $B$ presented only $1 \%$ of missing vegetation, while vineyard $C$ presented approximately $7 \%$.

Figure 13 presents a visual interpretation, based on the results obtained by applying the proposed method to plots A.04, A.06, A.07, B.02, and C.03. These plots differ in size and in vine rows coverage area. Some of the noticed limitations are related with the absence of vegetation or highly affected vines that did not developed properly. These 


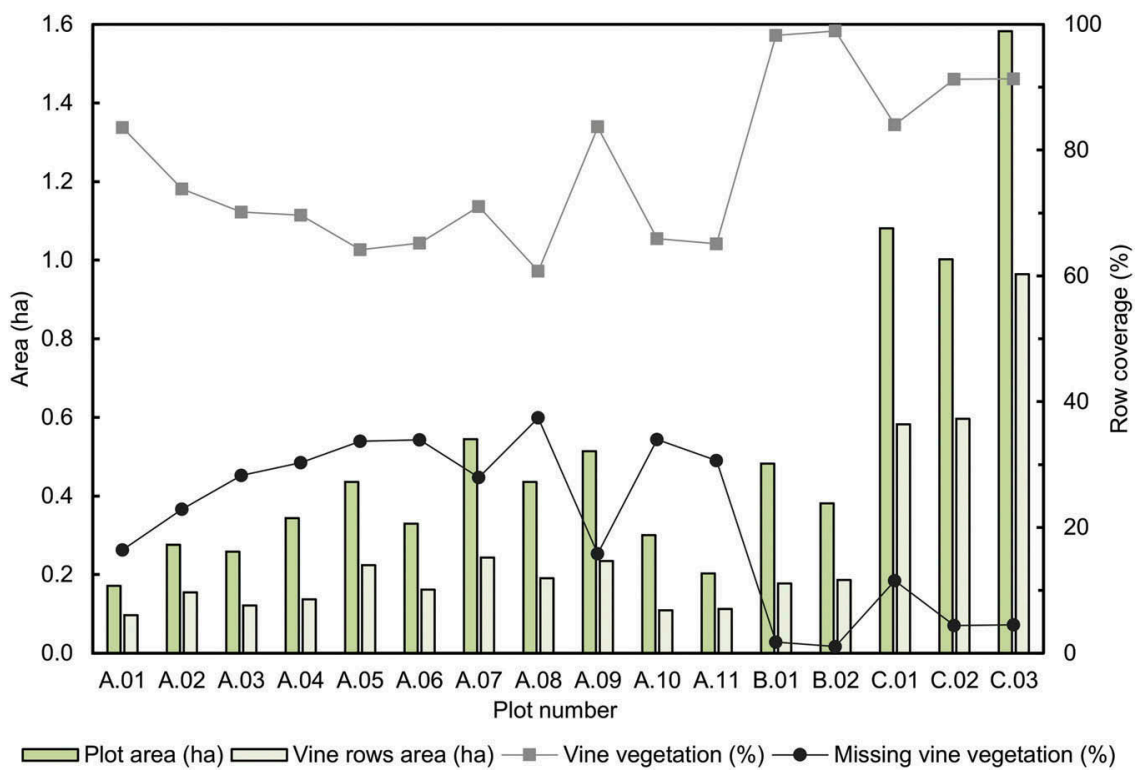

Figure 12. Area of the evaluated vineyard plots, along with vine rows occupation area, vines, and potential missing vines percentage.

issues resulted in lower heights that correspond to low vine rows formed. For example, in plot A.06 that was not classified, as can be seen in Figure 13(b). Green vegetation cover was considered as vegetation in plot A.07 (shown in Figure 13(c)). In plot B.02, vegetation absence in the estimated row centre caused an overestimation of missing vine vegetation (shown in Figure 13(d)).

The processing time spent in each vineyard was $8 \mathrm{~min}$ and $45 \mathrm{~s}$ for vineyard $C$ and $5 \mathrm{~min}$ and $32 \mathrm{~s}$ for vineyard $A$. Noticeably in vineyard $B$, the method took about $47 \mathrm{~s}$ to complete the analysis due to the lower number of plots and the lesser amount of images' detail - lower number of pixels due to the higher flight altitude that results in a lower GSD. Processing time is not related with the number of plots under analysis but with the areas' characteristics. This can be observed in the time spent during the vineyard $C$ processing (only 3 plots were analysed) in comparison with vineyard A (11 plots analysed): vineyard $C$ took 3 min more to be completed. The average plot processing time was $30 \mathrm{~s}$ for vineyard A, 23 for vineyard B, and almost $3 \mathrm{~min}$ for vineyard $\mathrm{C}$.

\section{Conclusions and future work}

In this article, a method to extract vineyard vegetation from high-resolution aerial imaginary is presented. It combines the benefits of VIs and CSM along with image processing techniques to automatically extract vine plot-related parameters, overcoming the presence of inter-row vegetation and canopies shadowing effects. The method is able to estimate missing vegetation and its correspondent overall percentage. It provides useful information about the current vineyard state, which can be used as a tool to be effectively applied in the management process within PV scope. The usage of relatively low-cost UAV with an RGB sensor proved to have enough accuracy to detect 
(a)

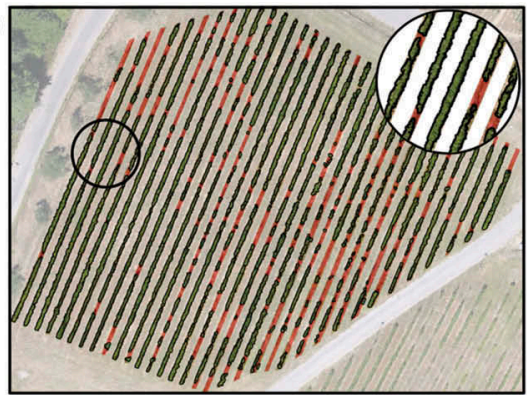

(c)

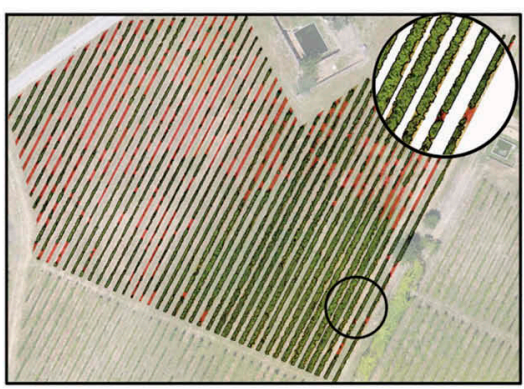

(b)

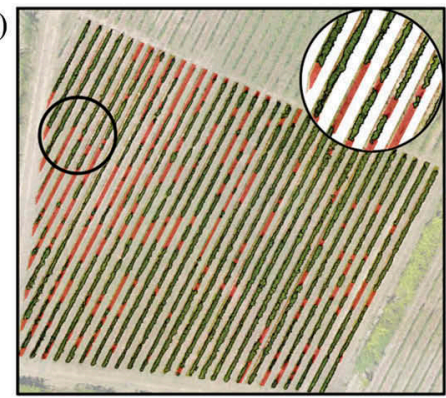

(d)

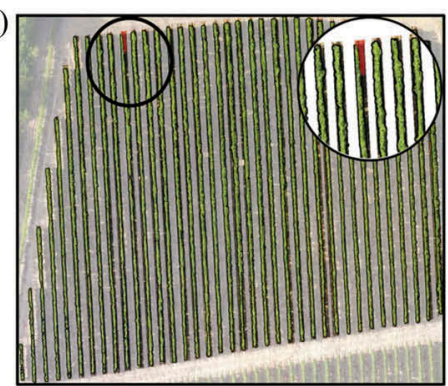

(e)

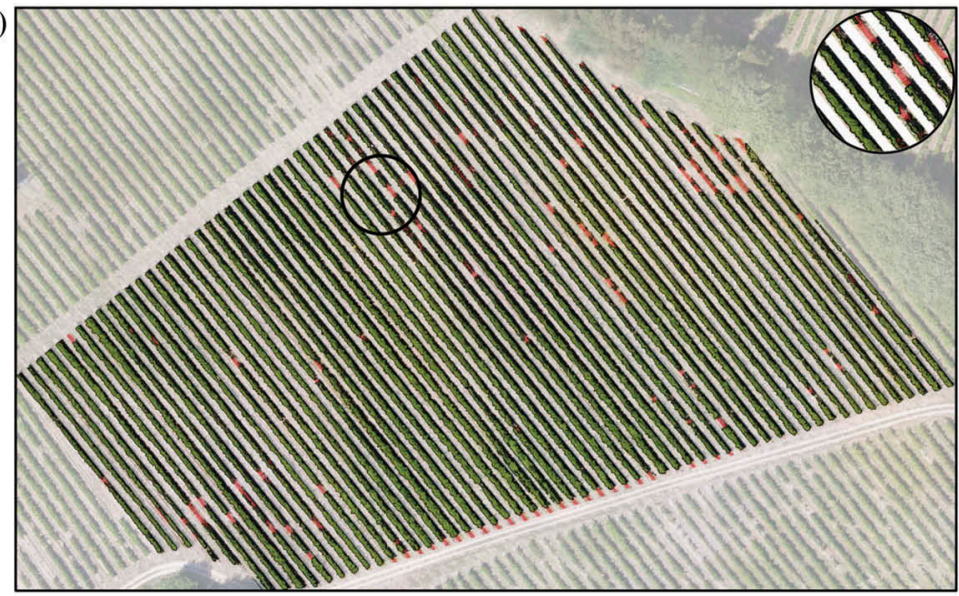

Figure 13. Results obtained by applying the proposed method to plots 4,6 , and 7 from vineyard $A$, plot 2 from vineyard B, and plot 3 from vineyard C. Faded RGB images are used as background; detected vegetation is represented in black and highlighted rows areas; and detected missing vegetation areas are represented in light red.

vineyard vegetation, being a cost-effective alternative to more expensive UAS and sensors used in PA surveys. The results obtained by applying the proposed method in RGB orthophoto mosaics and DTMs with very-high resolution (GSD from 2.4 to $3.8 \mathrm{~cm}$ ) demonstrated its efficiency in the estimation of vine rows $(94.45 \%)$, vine vegetation (94.10\%), and missing vines plants (97.04\%). These results are in line with other methods that use imagery data from more expensive sensors types, such as NIR. Misclassifications were noticeable in areas where vine vegetation suffered from neighbouring trees shadows and in vine rows constituted only by dead vine plants. Small variations in vegetation detection were noticeable in vine rows' edges. 
As future work, the proposed method will be applied at a multi-temporal level to detect possible biotic and abiotic problems in the vineyard and to study its in-season and inter-season evolution dynamics. Even though the used data was RGB, the method is also suitable to be applied alongside with multi-spectral or thermal UAS-based data. More parameters can be accurately estimated, such as vine vegetation vigour and water status, crucial to assist in the application of crop-variable treatments and irrigation scheduling. The presented method has also potential to be applied in different crops with the same row-oriented plantation structure, as fruit orchards and vegetable crops. The usage of UAVs can be useful to automate vineyard management using unmanned ground vehicles and/or ground sensors, from soil and meteorological data. It is also intended to provide the ability to automatically detect vine plots and to interpret its plantation shape type, so that correct methodologies can be applied in vine vegetation detection and analysis. Data acquisition parameters must be studied (altitude, image overlap, UAV speed, camera angle, or resolution) to evaluate its influence in the photogrammetric processing to ensure maximum data quality.

\section{Acknowledgements}

This work was supported by the ERDF and North 2020 - North Regional Operational Program, as part of project 'INNOVINEandWINE - Vineyard and Wine Innovation Platform' (NORTE-01-0145FEDER-000038).

\section{Disclosure statement}

No potential conflict of interest was reported by the authors.

\section{Funding}

This work was financed by the European Regional Development Fund (ERDF) through the Operational Programme for Competitiveness and Internationalisation - COMPETE 2020 under the PORTUGAL 2020 Partnership Agreement and through the Portuguese National Innovation Agency (ANI) as a part of project 'PARRA - Plataforma integrAda de monitoRização e avaliação da doença da flavescência douRada na vinhA' (No 3447).

\section{ORCID}

Luís Pádua (10) http://orcid.org/0000-0002-7570-9773

Telmo Adão (1) http://orcid.org/0000-0002-2727-0014

António Sousa (1) http://orcid.org/0000-0002-9269-6855

Emanuel Peres (1) http://orcid.org/0000-0001-5669-7976

Raul Morais (1) http://orcid.org/0000-0003-2440-9153

Joaquim J. Sousa (1) http://orcid.org/0000-0003-4533-930X 


\section{References}

Albetis, J., S. Duthoit, F. Guttler, A. Jacquin, M. Goulard, H. Poilvé, J.-B. Féret, and G. Dedieu. 2017. "Detection of Flavescence Dorée Grapevine Disease Using Unmanned Aerial Vehicle (UAV) Multispectral Imagery." Remote Sensing 9 (4): 308. doi:10.3390/rs9040308.

Baluja, J., M. P. Diago, P. Balda, R. Zorer, F. Meggio, F. Morales, and J. Tardaguila. 2012. "Assessment of Vineyard Water Status Variability by Thermal and Multispectral Imagery Using an Unmanned Aerial Vehicle (UAV)." Irrigation Science 30 (6): 511-522. doi:10.1007/s00271-012-0382-9.

Baofeng, S., X. Jinru, X. Chunyu, F. Yulin, S. Yuyang, and S. Fuentes. 2016. "Digital Surface Model Applied to Unmanned Aerial Vehicle Based Photogrammetry to Assess Potential Biotic or Abiotic Effects on Grapevine Canopies." International Journal of Agricultural and Biological Engineering 9 (6): 119.

Bellvert, J., and J. Girona. 2012. "The Use of Multispectral and Thermal Images as a Tool for Irrigation Scheduling in Vineyards." Erena, M.; López-Francos, A.; Montesinos, S. Y Berthoumieu, JF (2012):«The Use of Remote Sensing and Geographic Information Systems for Irrigation Management in Southwest Europe». Options MéditerranéenneS. Serie B: Studies and Researchs 67: 131-137.

Bellvert, J., P. J. Zarco-Tejada, J. Girona, and E. Fereres. 2013. “Mapping Crop Water Stress Index in a 'PinotNoir' Vineyard: Comparing Ground Measurements with Thermal Remote Sensing Imagery from an Unmanned Aerial Vehicle." Precision Agriculture 15 (4): 361-376. doi:10.1007/s11119-013-9334-5.

Bendig, J., Y. Kang, H. Aasen, A. Bolten, S. Bennertz, J. Broscheit, M. L. Gnyp, and G. Bareth. 2015. "Combining UAV-Based Plant Height from Crop Surface Models, Visible, and near Infrared Vegetation Indices for Biomass Monitoring in Barley." International Journal of Applied Earth Observation and Geoinformation 39 (Jul.): 79-87. doi:10.1016/j.jag.2015.02.012.

Bobillet, W., J.P. Da Costa, C. Germain, O. Lavialle, and G. Grenier. 2003. "Row Detection in High Resolution Remote Sensing Images Of Vine Fields." In Proceedings of the 4th European Conference on Precision Agriculture, 81-87. Berlin, Germany: Wageningen Academic Publishers.

Burgos, S., M. Mota, D. Noll, and B. Cannelle. 2015. "Use of Very High-Resolution Airborne Images to Analyse 3D Canopy Architecture of a Vineyard." The International Archives of Photogrammetry, Remote Sensing and Spatial Information Sciences 40 (3): 399. doi:10.5194/isprsarchives-XL-3-W3399-2015.

Chanussot, J., P. Bas, and L. Bombrun. 2005. "Airborne Remote Sensing of Vineyards for the Detection of Dead Vine Trees." In Proceedings of the Geoscience and Remote Sensing Symposium (IGARSS), 5: 3090-3093. Seoul, South Korea: IEEE International. doi: 10.1109/ IGARSS.2005.1526490.

Comba, L., P. Gay, J. Primicerio, and D. R. Aimonino. 2015. "Vineyard Detection from Unmanned Aerial Systems Images." Computers and Electronics in Agriculture 114 (June): 78-87. doi:10.1016/j. compag.2015.03.011.

Falkowski, M. J., P. E. Gessler, P. Morgan, A. T. Hudak, and A. M. S. Smith. 2005. "Characterizing and Mapping Forest Fire Fuels Using ASTER Imagery and Gradient Modeling." Forest Ecology and Management 217 (2): 129-146. doi:10.1016/j.foreco.2005.06.013.

Fraga, H., M. Amraoui, A. C. Malheiro, J. Moutinho-Pereira, J. Eiras-Dias, J. Silvestre, and J. A. Santos. 2014. "Examining the Relationship between the Enhanced Vegetation Index and Grapevine Phenology." European Journal of Remote Sensing 47 (1): 753-771. doi:10.5721/ EuJRS20144743.

Gitelson, A. A., Y. J. Kaufman, R. Stark, and D. Rundquist. 2002. "Novel Algorithms for Remote Estimation of Vegetation Fraction." Remote Sensing of Environment 80 (1): 76-87. doi:10.1016/ S0034-4257(01)00289-9.

Gobron, N., B. Pinty, M. M. Verstraete, and J. L. Widlowski. 2000. "Advanced Vegetation Indices Optimized for up-Coming Sensors: Design, Performance, and Applications." IEEE Transactions on Geoscience and Remote Sensing 38 (6): 2489-2505. doi:10.1109/36.885197.

Holman, F. H., A. B. Riche, A. Michalski, M. Castle, M. J. Wooster, and M. J. Hawkesford. 2016. “High Throughput Field Phenotyping of Wheat Plant Height and Growth Rate in Field Plot Trials Using UAV Based Remote Sensing." Remote Sensing 8 (12): 1031. doi:10.3390/rs8121031. 
Hunt, E. R., P. C. Doraiswamy, J. E. McMurtrey, C. S. T. Daughtry, E. M. Perry, and B. Akhmedov. 2013. "A Visible Band Index for Remote Sensing Leaf Chlorophyll Content at the Canopy Scale." International Journal of Applied Earth Observation and Geoinformation 21 (April): 103-112. doi:10.1016/j.jag.2012.07.020.

Johnson, L. F., D. E. Roczen, S. K. Youkhana, R. R. Nemani, and D. F. Bosch. 2003. "Mapping Vineyard Leaf Area with Multispectral Satellite Imagery." Computers and Electronics in Agriculture 38 (1): 33-44. doi:10.1016/S0168-1699(02)00106-0.

Kalisperakis, I., C. Stentoumis, L. Grammatikopoulos, and K. Karantzalos. 2015. "Leaf Area Index Estimation in Vineyards from UAV Hyperspectral Data, 2D Image Mosaics and 3D Canopy Surface Models." The International Archives of Photogrammetry, Remote Sensing and Spatial Information Sciences 40 (1): 299. doi:10.5194/isprsarchives-XL-1-W4-299-2015.

Kawashima, S., and M. Nakatani. 1998. "An Algorithm for Estimating Chlorophyll Content in Leaves Using a Video Camera." Annals of Botany 81 (1): 49-54. doi:10.1006/anbo.1997.0544.

Lacar, F. M., M. M. Lewis, and I. T. Grierson. 2001. “Use of Hyperspectral Imagery for Mapping Grape Varieties in the Barossa Valley, South Australia." In Proceedings of the Geoscience and Remote Sensing Symposium (IGARSS), 6: 2875-2877. Sydney, Australia: IEEE International. doi: 10.1109/ IGARSS.2001.978191.

Lamb, D. W., M. M. Weedon, and R. G. V. Bramley. 2004. “Using Remote Sensing to Predict Grape Phenolics and Colour at Harvest in a Cabernet Sauvignon Vineyard: Timing Observations against Vine Phenology and Optimising Image Resolution." Australian Journal of Grape and Wine Research 10 (1): 46-54. doi:10.1111/j.1755-0238.2004.tb00007.x.

Martín, P., P. J. Zarco-Tejada, M. R. González, and A. Berjón. 2015. “Using Hyperspectral Remote Sensing to Map Grape Quality in 'Tempranillo' Vineyards Affected by Iron Deficiency Chlorosis." VITIS - Journal of Grapevine Research 46 (1): 7.

Matese, A., J. Primicerio, F. Di Gennaro, E. Fiorillo, F. P. Vaccari, and L. Genesio. 2013. “Development and Application of an Autonomous and Flexible Unmanned Aerial Vehicle for Precision Viticulture." Acta Horticulturae 978 (March): 63-69. doi:10.17660/ActaHortic.2013.978.5.

Matese, A., P. Toscano, S. F. D. Gennaro, L. Genesio, F. P. Vaccari, J. Primicerio, C. Belli, A. Zaldei, R. Bianconi, and B. Gioli. 2015. "Intercomparison of UAV, Aircraft and Satellite Remote Sensing Platforms for Precision Viticulture." Remote Sensing 7 (3): 2971-2990. doi:10.3390/rs70302971.

Matese, A., S. F. D. Gennaro, and A. Berton. 2016. "Assessment of a Canopy Height Model (CHM) in a Vineyard Using UAV-Based Multispectral Imaging." International Journal of Remote Sensing. September 1-11. doi:10.1080/01431161.2016.1226002.

Mathews, A. J., and J. L. R. Jensen. 2013. "Visualizing and Quantifying Vineyard Canopy LAI Using an Unmanned Aerial Vehicle (UAV) Collected High Density Structure from Motion Point Cloud." Remote Sensing 5 (5): 2164-2183. doi:10.3390/rs5052164.

Naidu, R. A., E. M. Perry, F. J. Pierce, and T. Mekuria. 2009. "The Potential of Spectral Reflectance Technique for the Detection of Grapevine Leafroll-Associated Virus-3 in Two Red-Berried Wine Grape Cultivars." Computers and Electronics in Agriculture 66 (1): 38-45. doi:10.1016/j. compag.2008.11.007.

Nolan, A. P., S. Park, M. O'Connell, S. Fuentes, D. Ryu, and H. Chung. 2015. Automated Detection and Segmentation of Vine Rows Using High Resolution UAS Imagery in a Commercial Vineyard. Gold Coast, Australia. https://www.researchgate.net/profile/Mark_Oconnell/publication/284206199_ Automated_detection_and_segmentation_of_vine_rows_using_high_resolution_UAS_ima gery_in_a_commercial_vineyard/links/566e1c9f08ae1a797e405f39.pdf.

Otsu, N. 1979. "A Threshold Selection Method from Gray-Level Histograms." IEEE Transactions on Systems, Man, and Cybernetics 9 (1): 62-66. doi:10.1109/TSMC.1979.4310076.

Pádua, L., J. Vanko, J. Hruška, J. J. Telmo Adão, E. P. Sousa, and R. Morais. 2017. "UAS, Sensors, and Data Processing in Agroforestry: A Review Towards Practical Applications." International Journal of Remote Sensing 38 (8-10): 2349-2391. doi:10.1080/01431161.2017.1297548.

Poblete-Echeverría, C., G. F. Olmedo, B. Ingram, and M. Bardeen. 2017. "Detection and Segmentation of Vine Canopy in Ultra-High Spatial Resolution RGB Imagery Obtained from Unmanned Aerial Vehicle (UAV): A Case Study in a Commercial Vineyard." Remote Sensing 9 (3): 268. doi:10.3390/rs9030268. 
Primicerio, J., G. Caruso, L. Comba, A. Crisci, P. Gay, S. Guidoni, L. Genesio, D. R. Aimonino, and F. P. Vaccari. 2017. "Individual Plant Definition and Missing Plant Characterization in Vineyards from High-Resolution UAV Imagery." European Journal of Remote Sensing 50 (1): 179-186. doi:10.1080/22797254.2017.1308234.

Primicerio, J., P. Gay, D. R. Aimonino, L. Comba, A. Matese, and S. F. Di Gennaro. 2015. “NDVI-Based Vigour Maps Production Using Automatic Detection of Vine Rows in Ultra-High Resolution Aerial Images." Precision Agriculture 15: 465-470. Wageningen Academic Publishers http:// www.wageningenacademic.com/doi/abs/10.3920/978-90-8686-814-8_57.

Proffitt, A. P. B., R. Bramley, D. Lamb, and E. Winter. 2006. Precision Viticulture: A New Era in Vineyard Management and Wine Production. Ashford, Australia: Winetitles.

Puletti, N., R. Perria, and P. Storchi. 2014. "Unsupervised Classification of Very High Remotely Sensed Images for Grapevine Rows Detection." European Journal of Remote Sensing 47 (1): 4554. doi:10.5721/EuJRS20144704.

Richardson, A. D., J. P. Jenkins, B. H. Braswell, D. Y. Hollinger, S. V. Ollinger, and M.-L. Smith. 2007. "Use of Digital Webcam Images to Track Spring Green-Up in a Deciduous Broadleaf Forest." Oecologia 152 (2): 323-334. doi:10.1007/s00442-006-0657-z.

Smit, J. L., G. Sithole, and A. E. Strever. 2010. "Vine Signal Extraction - An Application of Remote Sensing in Precision Viticulture." South African Journal of Enology and Viticulture 31 (2): 65-74.

Tucker, C. J. 1979. "Red and Photographic Infrared Linear Combinations for Monitoring Vegetation." Remote Sensing of Environment 8 (2): 127-150. doi:10.1016/0034-4257(79)90013-0.

Ward, J. H. Jr. 1963. "Hierarchical Grouping to Optimize an Objective Function." Journal of the American Statistical Association 58 (301): 236-244. doi:10.1080/01621459.1963.10500845.

Weiss, M., and F. Baret. 2017. "Using 3D Point Clouds Derived from UAV RGB Imagery to Describe Vineyard 3D Macro-Structure." Remote Sensing 9 (2): 111. doi:10.3390/rs9020111.

Woebbecke, D. M., G. E. Meyer, K. Von Bargen, and D. A. Mortensen. 1995. "Color Indices for Weed Identification under Various Soil, Residue, and Lighting Conditions." Transactions of the ASAE 38 (1): 259. doi: 10.13031/2013.27838.

Zarco-Tejada, P. J., A. Berjón, and J. R. Miller. 2004. "Stress Detection in Crops with Hyperspectral Remote Sensing and Physical Simulation Models." In Proceedings of the Airborne Imaging Spectroscopy Workshop, Bruges, Belgium.

Zarco-Tejada, P. J., A. Berjón, R. López-Lozano, J. R. Miller, P. Martín, V. Cachorro, M. R. González, and A. De Frutos. 2005. "Assessing Vineyard Condition with Hyperspectral Indices: Leaf and Canopy Reflectance Simulation in a Row-Structured Discontinuous Canopy." Remote Sensing of Environment 99 (3): 271-287. doi:10.1016/j.rse.2005.09.002.

Zarco-Tejada, P. J., N. Hubbard, and P. Loudjani. 2014. Precision Agriculture: An Opportunity for EU Farmers - Potential Support with the CAP 2014-2020. Technical Report. Brussels, Belgium: Joint Research Centre (JRC) of the European Commission Monitoring Agriculture Resources (MARS). 